\title{
Slack-moored semi-submersible wind floater with damping plates in waves: linear diffraction modelling with mean forces and experiments
}

DOI:

10.1016/j.jfluidstructs.2019.07.010

\section{Document Version}

Accepted author manuscript

Link to publication record in Manchester Research Explorer

Citation for published version (APA):

Stansby, P., Carpintero Moreno, E., Apsley, D., \& Stallard, T. (2019). Slack-moored semi-submersible wind floater with damping plates in waves: linear diffraction modelling with mean forces and experiments. JOURNAL OF FLUIDS AND STRUCTURES, 90, 410-431. https://doi.org/10.1016/j.jluidstructs.2019.07.010

Published in:

JOURNAL OF FLUIDS AND STRUCTURES

\section{Citing this paper}

Please note that where the full-text provided on Manchester Research Explorer is the Author Accepted Manuscript or Proof version this may differ from the final Published version. If citing, it is advised that you check and use the publisher's definitive version.

\section{General rights}

Copyright and moral rights for the publications made accessible in the Research Explorer are retained by the authors and/or other copyright owners and it is a condition of accessing publications that users recognise and abide by the legal requirements associated with these rights.

\section{Takedown policy}

If you believe that this document breaches copyright please refer to the University of Manchester's Takedown Procedures [http://man.ac.uk/04Y6Bo] or contact uml.scholarlycommunications@manchester.ac.uk providing relevant details, so we can investigate your claim.

\section{OPEN ACCESS}


Slack-moored semi-submersible wind floater with damping plates in waves: linear diffraction modelling with mean forces and experiments

P.K. Stansby , E. Carpintero Moreno, D.D. Apsley, T.J. Stallard

School of Mechanical, Aerospace and Civil Engineering, University of Manchester, UK

Abstract

A semi-submersible wind platform with four floats of equal diameter, damping plates and relatively small drafts has been designed to support a $5 \mathrm{MW}$ wind turbine at full scale. Motion and mooring forces from wave basin measurements have been compared with time domain linear diffraction modelling accounting for drag forces, mooring forces and mean forces due to zero-difference frequency components, as is standard, and due to damping associated with radiation and drag forces, not previously considered. The platform response in the form of rms acceleration is quite well predicted although peak values can be underestimated. The mean mooring forces are underestimated and peak values are considerably underestimated. In large waves moorings experience high snatch loads. The measured mean forces were applied in the model for further comparison. The mooring was primarily designed to prevent drift of the floater and improved designs could eliminate or reduce snatch loads. However, it is shown that hub acceleration is quite moderate, with peak values less than $4 \mathrm{~m} / \mathrm{s}^{2}$ in even the largest waves. The rms platform acceleration is largely decoupled from the mooring forces, as shown by corresponding spectra. In extreme conditions hydrodynamic mooring forces require nonlinear effects due to steep, sometimes breaking, waves to be accounted for. The wind thrust is included in the model using a coefficient from blade element momentum theory based on relative wind velocity. The peak hydrodynamic force would be significantly larger than the maximum wind thrust although the mean hydrodynamic force is significantly smaller. A practical conclusion is that a semi-sub floater with damping plates giving sufficiently low accelerations for operation in large waves may be of relatively shallow draft, less than the depths of many ports which is convenient for deployment.

Keywords: wind floater; multi-float with damping plates; slack moored; linear diffraction; mean forces; experimental comparison

\section{Introduction}

Offshore is the new energy frontier and wind turbines are an established technology. Floating platforms enable wind energy conversion in deeper water than fixed platforms, for depths larger than about $30 \mathrm{~m}$ where the resource is generally greater. There are three main types of floater: spar $[32,34]$, tension leg platform (TLP) $[18,21,26]$ and semi-submersible $[2,13,28]$. The spar has a large draft for stability suitable for very deep water, the TLP has high tension mooring lines to restrict rotation and the 'semi-sub' has a large plan area for stability and relatively shallow draft convenient for deployment $[12,19,20]$. A semi-sub tethered to a single point mooring buoy, known as slack moored, is considered here. An important question is whether the platform motion is small enough to allow normal wind turbine operation for the range of wave and wind conditions experienced offshore. Hub acceleration greater than $4 \mathrm{~m} / \mathrm{s}^{2}$ is said to limit operation, providing a useful guideline [3]. To reduce motion horizontal damping plates are generally attached to the base of the floats [2, 34,36]. We consider a four float system shown in Fig.1 with three mid floats (the central one 
supporting the wind turbine column) and a bow float of larger draft; all diameters are equal and the floats are effectively rigidly connected by beams at deck level. The wind turbine mass and inertia are based on the NREL 5 MW turbine [16] and the inclined rods shown in Fig.1 are included to prevent dynamic response in the laboratory model. The criteria for floater dimensions are quite simple. The drafts at full scale should be less than $9 \mathrm{~m}$ which is the depth available for float out in many ports [3]. The diameters should be as small as possible but large enough for the 3 mid floats to provide sufficient buoyancy to support the wind turbine and column with little ballast. The distance from mid to bow float should be large enough for the overturning moment due to the greatest wind turbine thrust to be balanced by the moment due to the restoring buoyancy force with the bow float base remaining submerged. The bow float draft will be greater than that for mid floats but less than $9 \mathrm{~m}$ at full scale, requiring greater ballast to give the same freeboard. The aim is that the draft with maximum wind thrust should be about half that in still-water conditions. The dimensions shown in Fig.2 at a model scale of 1:50 approximately satisfy these criteria and could be optimised further by hydrodynamic analysis, once established. The simple mooring consists of a small buoy with an inextensible cord connecting to the bed and another cord connecting to the bow float. The wave drift force causes alignment of the floater centreline with the wave direction, assumed to be aligned with the wind direction for this study; mooring forces are analysed as part of a coupled system.

The primary aim of the study is to determine the motion of such a floater across a range of wave conditions and wind speeds for turbine operation. For this purpose accelerations are analysed. Experiments are undertaken in a wave basin without wind, and hydrodynamic analysis is based on linear diffraction modelling. This is standard practice in offshore engineering with various potential flow panel codes available to provide diffraction force coefficients for fixed platforms and additional added mass and radiation damping coefficients for responding bodies. Empirical drag effects may be superimposed, which are large for damping plates. This approach has been applied in both the frequency and time domains to floating wind energy platforms and wave energy converters (WECs) $[9,17,33,35]$. Second-order forces due to sum and difference frequency components in irregular waves have been added though quadratic transfer functions $[8,27]$. We use the commercial industry standard panel code WAMIT to provide force coefficients [22]. For floating wind platforms only stationary-body second order forces are included in the time domain NREL FAST code based on Cummins method [8], following [21].

The wind turbine thrust is simply modelled by an instantaneous coefficient based on relative wind velocity from blade element momentum theory (BEMT). Effects of drag and thrust are highly nonlinear and time domain modelling is thus necessary; associated mooring forces are also highly nonlinear and 'snatch' loads can occur. While $2^{\text {nd }}$ order hydrodynamic forces for stationary bodies due to difference and sum frequencies, which include mean forces, are generally included in such modelling [8], there are additional $2^{\text {nd }}$ order forces due to body motion associated with radiation and drag damping. These have been included in frequency domain analysis with linear representation (B.Molin private communication and [27]) but not in time domain modelling to our knowledge. The additional mean forces are due to mean energy flux in the waves being absorbed in damping due to body motion. A mean force times a wave speed provides the energy flux for this energy absorption. This has been discussed for two dimensional problems with wave reflection and radiation in [25], section 7.10, but not for general three-dimensional problems of interest here (to our knowledge). Second-order order forces due to difference frequencies generally contain low frequency components which, although small, may excite natural frequencies of a floater with a small mooring 
stiffness when mechanical damping is also small [21]. These low frequency drift motions may be problematic. In a slack-moored system there is negligible mechanical stiffness but there will be some hydrodynamic stiffness due to the varying submergence of the mooring buoy. However the small slowly varying second-order forces due to body motion are not known and only mean forces are considered here. These require knowledge of the body motions which are not known initially and are first estimated from purely linear modelling. The secondary aim is thus to determine the nature of mooring forces and assess the limitations of linear diffraction modelling (with mean forces) for their prediction.

In general it may be said that a fully nonlinear potential-flow or computational fluid dynamics (CFD) model will give motions directly. However such computations are invariably very time consuming $[15,26,30]$, sometimes requiring hours or days on multi processors and can be inaccurate. The linear computations with mean force effects on the other hand take the order of one minute on a laptop, even for multi-bodies (once the hydrodynamic coefficients have been obtained), and the physical origins of various effects may be identified. Fast computations are obviously desirable for design where geometries and configurations need to be optimised.

For wave energy point absorbers various levels of nonlinear forcing, notably Froude-Krylov, have been assessed [10]. Froude-Krylov forcing for a taut-moored buoy has been shown to predict response with remarkable accuracy by [23]. Both [10] and [23] assume that the wave profile around the body is unaffected which is less likely with multiple float interaction. Moorings have been coupled with the CFD package Open FOAM $[24,30]$ and the SPH (smoothed particle hydrodynamics) package DualSPHysics [6] using the mooring package MoorDyn [13], again for single floats. Such methods have yet to be applied with multiple floats. Mooring systems and analysis have been reviewed in [7].

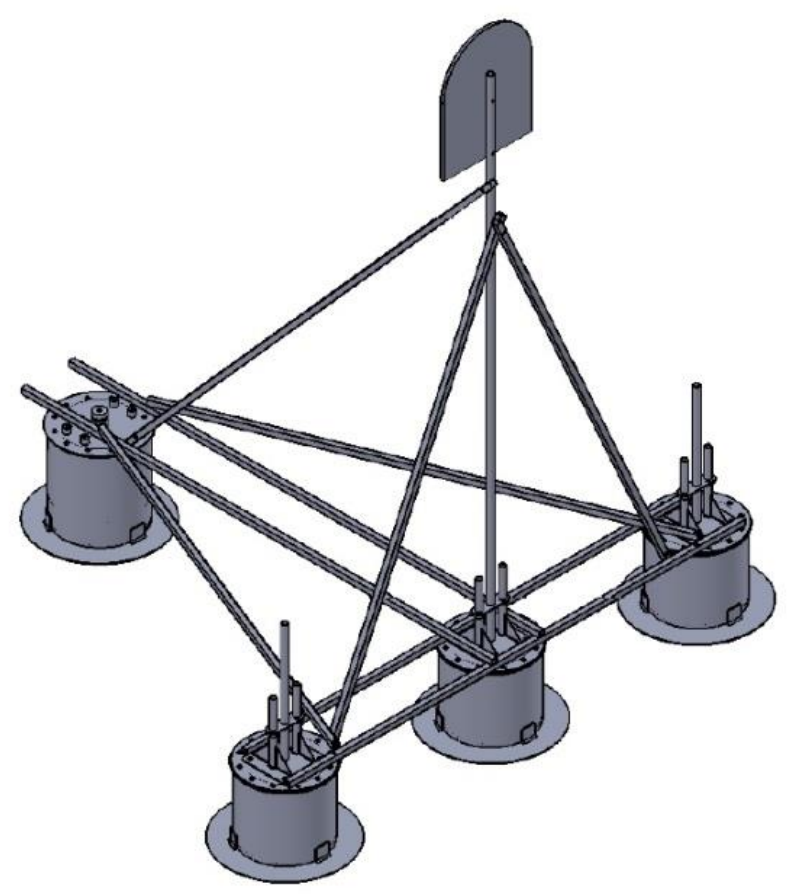

Fig.1 The 4-float configuration with approximate NREL $5 \mathrm{MW}$ wind turbine mass/inertia distribution. Overall dimensions are approximately: $1.5 \mathrm{~m}$ long, $1.6 \mathrm{~m}$ wide and $1.6 \mathrm{~m}$ from deck to hub. 
The paper is organised as follows. The next section describes the dynamic multi-float model, the hydrodynamic forces and the mooring model. The following section summarises the experimental arrangement. Model results are then compared with experiment. These are discussed in the next section and some conclusions are made.

\section{Mathematical formulation and model}

The multi-float time-domain formulation is first provided where hydrodynamic forces are due to linear wave excitation or diffraction, added mass, radiation damping, restoring, mean hydrodynamic and wind forces. Their definitions with WAMIT coefficients then follow, applied using Cummins method for irregular waves, following [33] for wave energy conversion. The standard form of the JONSWAP wave spectrum will be used. Fig. 2 shows the plan and elevation of the laboratory model, intended to be 1:50 scale.

a)

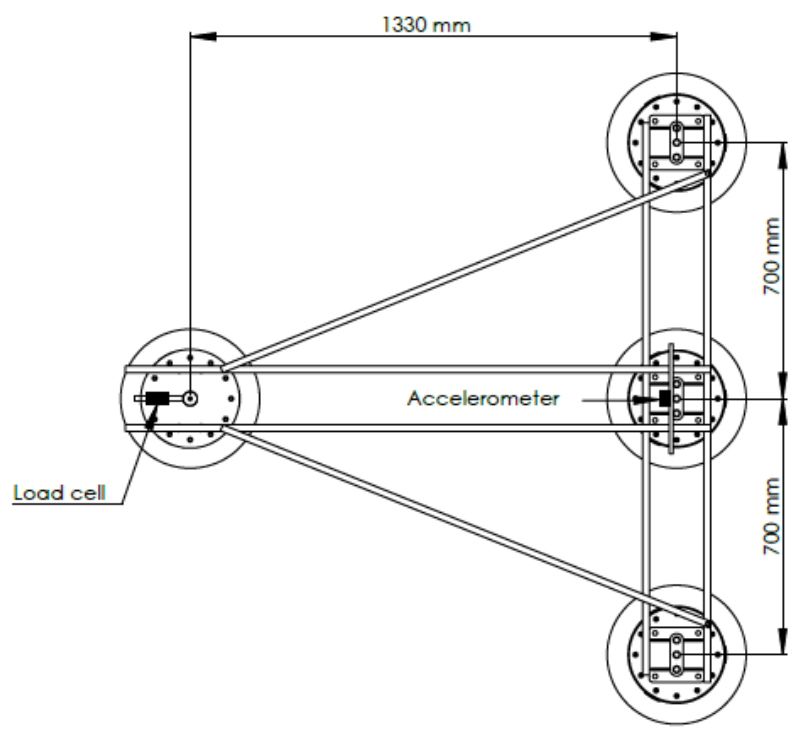


b)

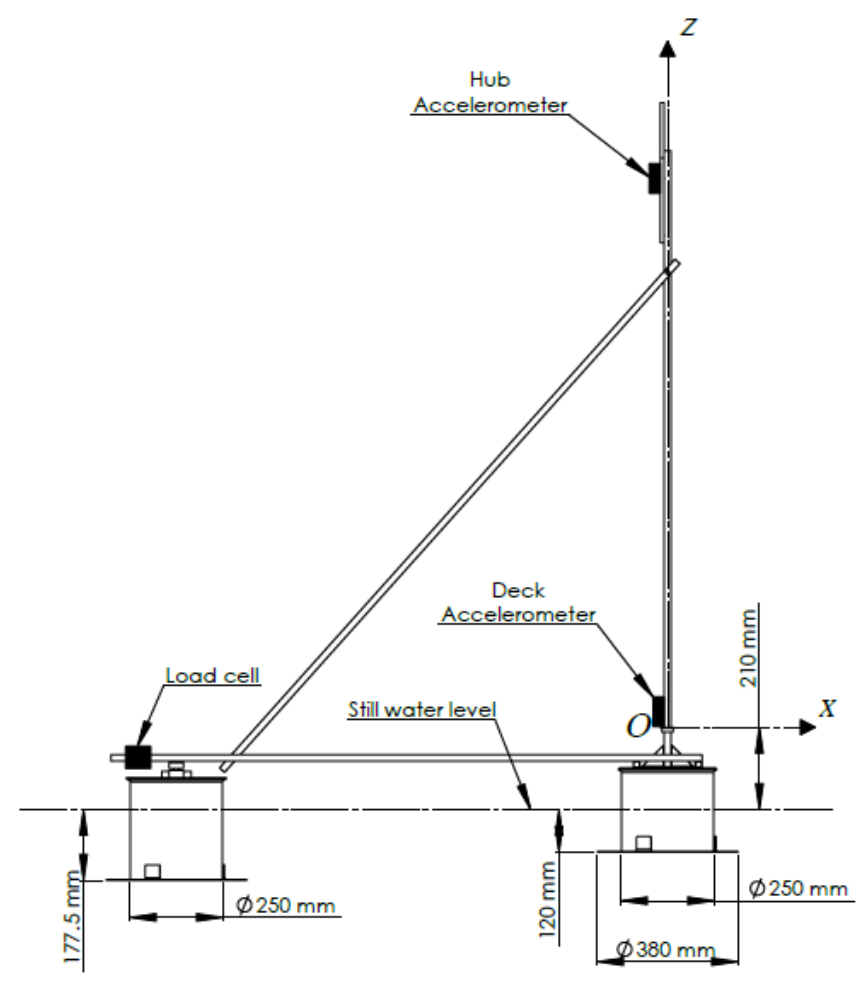

Fig.2 a) plan view of system and b) mid section elevation with dimensions and reference position 0.

Angular rotation $\theta$ is clockwise positive, $h$ is longitudinal horizontal distance from reference point $O$ positive in the stern direction, $v$ is vertical distance from $O$ positive below $O$. $H$ and $V$ are total hydrodynamic forces in conventional $x, z$ directions, $M$ is pitch moment.

There are $N$ floats considered as a single body as shown in Fig.2. Taking moments about a reference point $\mathrm{O}$ accounting for mooring force and all $N_{m}$ masses (floats, ballast, beams, turbine)

$-\sum_{i=1}^{N_{m}} m_{i} v_{i} \ddot{x}_{i}-\sum_{i=1}^{N_{m}} m_{i} h_{i} \ddot{z}_{i}+I \ddot{\theta}=M_{\text {wind }}+\sum_{i=1}^{N} M_{i}-\sum_{i=1}^{N} h_{i} V_{i}-\sum_{i=1}^{N} v_{i} H_{i}+v_{M} H_{M}-h_{M} V_{M}$

$I$ is moment of inertia about centre of mass, $M_{\text {wind }}$ is due to turbine thrust $H_{\text {wind }}$ defined below; $H_{M}$ and $V_{M}$ are horizontal and vertical mooring forces acting on the bow float, also defined below.

In the longitudinal horizontal direction

$\sum_{i=1}^{N_{m}} m_{i} \ddot{x}_{i}=\sum_{i=1}^{N} H_{i}+H_{w i n d}-H_{M}$

and in the vertical direction

$\sum_{i=1}^{N_{m}} m_{i} \ddot{z}_{i}=\sum_{i=1}^{N} V_{i}-V_{M}$ 
The positions of each float $x_{i}, z_{i}$, taken to be the centre of buoyancy, in relation to 0 , linearised for small angles, are defined by:

For floats, $i=1, N$

$x_{i}=x_{O}-v_{i} \theta$

$z_{i}=z_{O}-h_{i} \theta$

And for the wind turbine hub position, $x_{h u b}$, at height $v_{h u b}$ above 0

$x_{h u b}=x_{O}-v_{h u b} \theta$

For this case the body centreline is aligned with the wave direction.

We thus have 3 equations for 3 unknowns $x_{O}, z_{O}, \theta$

$\begin{aligned}-\sum_{i=1}^{N_{m}} m_{i} v_{i}\left(\ddot{x}_{O}-v_{i} \ddot{\theta}\right)-\sum_{i=1}^{N_{m}} m_{i} h_{i}\left(\ddot{z}_{O}-h_{i} \ddot{\theta}\right)+I \ddot{\theta} & =M_{\text {wind }}+\sum_{i=1}^{N} M_{i}-\sum_{i=1}^{N} h_{i} V_{i}-\sum_{i=1}^{N} v_{i} H_{i} \\ & +v_{M} H_{M}-h_{M} V_{M}\end{aligned}$

Giving

$$
\begin{gathered}
\ddot{\theta}\left(\sum_{i=1}^{N_{m}} m_{i} v_{i}^{2}+\sum_{i=1}^{N_{m}} m_{i} h_{i}^{2}+I\right) \\
=\sum_{i=1}^{N_{m}} m_{i} v_{i} \ddot{x}_{O}+\sum_{i=1}^{N_{m}} m_{i} h_{i} \ddot{z}_{O}+M_{\text {wind }}+\sum_{i=1}^{N} M_{i}-\sum_{i=1}^{N} h_{i} V_{i}-\sum_{i=1}^{N} v_{i} H_{i} \\
\quad+v_{M} H_{M}-h_{M} V_{M}
\end{gathered}
$$

In the horizontal longitudinal direction

$\sum_{i=1}^{N_{m}} m_{i}\left(\ddot{x}_{O}-v_{i} \ddot{\theta}_{i}\right)=\sum_{i=1}^{N} H_{i}+H_{\text {wind }}-H_{M}$

giving

$\ddot{x}_{O} \sum_{i=1}^{N_{m}} m_{i}=\sum_{i=1}^{N} H_{i}+H_{\text {wind }}-H_{M}+\sum_{i=1}^{N_{m}} m_{i} v_{i} \ddot{\theta}_{i}$

and in the vertical

$\sum_{i=1}^{N_{m}} m_{i}\left(\ddot{z}_{O}-h_{i} \ddot{\theta}_{i}\right)=\sum_{i=1}^{N} V_{i}-V_{M}$ 
giving

$\ddot{z}_{O} \sum_{i=1}^{N_{m}} m_{i}=\sum_{i=1}^{N} V_{i}-V_{M}+\sum_{i=1}^{N_{m}} m_{i} h_{i} \ddot{\theta}_{i}$

We thus have equations for $\ddot{\theta}, \ddot{x}_{O}, \ddot{z}_{O}$ which are further complicated by $H_{i}, V_{i}, M_{i}$ defined below also being a function of $\ddot{\theta}, \ddot{x}_{O}, \ddot{z}_{O}$ and hydrodynamic (WAMIT) coefficients.

We are concerned with irregular waves which are specified by the standard JONSWAP spectrum $S(f)$ defined by a significant wave height $H_{s}$ and a peak frequency $f_{p}=1 / T_{p}$ where $T_{p}$ is the peak period; a standard peak enhancement factor $\gamma=3.3$ was applied. Although the measured spectrum was always close to the target the measured spectrum was input into the model. The surface elevation $\eta$ at the bow float may be defined by linear superposition of the discretised wave amplitude components

$\eta(t)=\sum_{k=1}^{K} a_{k} \cos \left(-k 2 \pi \Delta f t+\varphi_{r, k}\right)$

where the upper limit on frequency was generally $f_{\max }=4.0 \mathrm{~Hz}$, between 3 and 8 times $f_{p}$, $\Delta f=f_{\max } / K, a_{k}=\sqrt{2 S(f) \Delta f}$, and $\varphi_{r}$ is phase from a uniform random distribution between 0 and $2 \pi$. $K$ is generally set to 200 .

Hydrodynamic moments and forces are defined using WAMIT notation as shown in Table 1.

\begin{tabular}{|c|c|c|}
\hline \multicolumn{3}{|c|}{ WAMIT notation } \\
\hline Body i & Mode number & Symbol \\
\hline Surge & $1+6(\mathrm{i}-1)$ & $H$ \\
\hline Heave & $3+6(\mathrm{i}-1)$ & $V$ \\
\hline Pitch & $5+6(\mathrm{i}-1)$ & $M$ \\
\hline
\end{tabular}

Table 1 WAMIT mode notation

Linear diffraction forces and moments for each float are defined by frequency-dependent coefficients for amplitude $F$ and phase $\varphi$, or real and imaginary parts but the former is more convenient as there is already a random phase for each frequency component. For each float $i=1, N$ :

Pitch moment $M_{D 5+6(i-1)}=\sum_{k=1}^{K} a_{k} F_{5+6(i-1), k} \cos \left(-k 2 \pi \Delta f t+\varphi_{5+6(i-1), k}+\varphi_{r, k}\right)$

Vertical force $V_{D 3+6(i-1)}=\sum_{k=1}^{K} a_{k} F_{3+6(i-1), k} \cos \left(-k 2 \pi \Delta f t+\varphi_{3+6(i-1), k}+\varphi_{r, k}\right)$

Longitudinal horizontal force

$$
H_{D 1+6(i-1)}=\sum_{k=1}^{K} a_{k} F_{1+6(i-1), k} \cos \left(-k 2 \pi \Delta f t+\varphi_{1+6(i-1), k}+\varphi_{r, k}\right)
$$


In addition there are second order forces associated with sum and difference frequencies which are small but the zero-difference frequencies generate a mean force which can be significant for mooring forces. This mean force may also be obtained conveniently from momentum flux from linear theory. Both may be obtained from WAMIT and values were found to be almost identical. These drift forces are for stationary floats and there are additional horizontal mean forces due to the time-average power absorption related to drag $P_{d r a g}$, and power required by float motion to radiate waves $P_{\text {rad }}$.

The averaged power absorbed due to drag is due to the pitch moment $M_{\text {drag }}$, heave force $V_{\text {drag }}$ and surge force $H_{\text {drag }}$ (defined below) and is given by

$P_{\text {drag }}=-\sum_{i=1}^{N} \int_{t_{1}}^{t_{2}}\left(M_{\text {drag } i} \dot{\theta}_{i}+V_{\text {drag } i} \dot{z}_{i}+H_{\text {drag } i} \dot{x}_{i}\right) d t /\left(t_{2}-t_{1}\right)$

The averaged radiated wave power results from all floats driven by pitch moment $M^{\mathrm{rad}}$, heave force $V^{\text {rad }}$ and surge force $H^{\text {rad }}$, is given by

$P_{\text {rad }}=-\sum_{i=1}^{N} \int_{t_{1}}^{t_{2}}\left(M_{5+6(i-1)}^{r a d} \dot{\theta}_{i}+V_{3+6(i-1)}^{r a d} \dot{z}_{i}+H_{1+6(i-1)}^{r a d} \dot{x}_{i}\right) d t /\left(t_{2}-t_{1}\right)$

This is also of second order. The power absorbed from oncoming waves $\left(P_{\text {rad }}+P_{\text {drag }}\right)$ is balanced by the horizontal energy flux with a representative wave speed times a horizontal force $H^{\text {pow }}$. The average wave speed for a spectrum is based on the average group velocity $c_{e}$ of the spectrum. Thus $H^{\text {pow }}=\left(P_{\text {rad }}+P_{\text {drag }}\right) / c_{e}$. The same argument has been described for two-dimensional problems in [25], section 7.10. An additional consideration here concerns the split of $H^{\text {pow }}$ between floats and this is assumed simply to be in the same proportion as the horizontal momentum flux drift forces.

However the second-order mean forces due to wave power absorption are not known initially and the model is first run in a purely linear way without any mean force to give estimates for float motions. The model is then run again with mean forces and a mooring model to give the mooring forces. It will be seen that mooring force has little effect on motion. In general, more than one iteration may be desirable if the mooring forces affect the power capture and motion. We should also point out that the computer time for a run is small, order one minute on a laptop using Fortran.

Added mass and radiation damping forces and moments are defined by frequency-dependent coefficients $A$ and $B$ respectively using the Cummins method. With a single body and one degree of freedom $x$ we have

$m x \ddot{(t})=f(t)-A^{\infty} \ddot{x}(t)-\int_{-\infty}^{t} L(t-\tau) \dot{x}(\tau) d \tau$

where $f$ includes forces due to excitation, restoring and drag in this case; $A^{\infty}$ is added mass for infinite frequency, $\tau$ is time and the impulse response function for radiation damping is given by $L(t)=\frac{2}{\pi} \int_{0}^{\infty} B(\omega) \cos (\omega t) d \omega$

In discrete form with time step $\Delta t$, time $t=n \Delta t$ and $\omega=2 \pi f=k \Delta \omega$ 
$L^{m}=\frac{2}{\pi} \sum_{k=0}^{K} B_{k} \cos (k \Delta \omega n \Delta t) \Delta \omega$

which is precomputed and in discrete form

$-\int_{-\infty}^{t} L(t-\tau) \dot{x}(\tau) d \tau=-\sum_{l=n-2 \mathcal{M}}^{n} L^{n-l} \dot{x}^{l} \Delta \tau$

where $\Delta \tau=\Delta t$ and $\mathcal{M}=T_{p} / \Delta t$. The lower limit $(m-2 \mathcal{M})$ was generally used to represent $-\infty$ with almost identical results given by $(m-4 \mathcal{M})$.

The right hand side (RHS) is generalised for each float with 3 modes.

For each float $i=1, N$ moments are defined by:

$M_{i}=M_{D 5+6(i-1)}$

$-\sum_{j=1}^{N} A_{5+6(i-1), 5+6(j-1)}^{\infty} . \ddot{\theta}_{j}-\sum_{j=1}^{N} \int_{-\infty}^{t} L_{5+6(i-1), 5+6(j-1)}(t-\tau) \dot{\theta}_{j}(\tau) d \tau$

$-\sum_{j=1}^{N} A_{5+6(i-1), 1+6(j-1)}^{\infty} \cdot \ddot{x}_{j}-\sum_{j=1}^{N} \int_{-\infty}^{t} L_{5+6(i-1), 1+6(j-1)}(t-\tau) \dot{x}_{j}(\tau) d \tau$

$-\sum_{j=1}^{N} A^{\infty}{ }_{5+6(i-1), 3+6(j-1)} \cdot \ddot{z}_{j}-\sum_{j=1}^{N} \int_{-\infty}^{t} L_{5+6(i-1), 3+6(j-1)}(t-\tau) \dot{z}_{j} d \tau$

$+M_{\text {rest } i}+M_{\text {drag } i}+M_{\text {mean } i}$

where the subscripts rest, drag and mean indicate restoring and drag moments to be described below and mean has been described above.

As an example the discrete form of the term is given by

$$
-\sum_{j=1}^{N} \int_{-\infty}^{t} L_{5+6(i-1), 5+6(j-1)}(t-\tau) \dot{\theta}_{j}(j) d \tau=-\sum_{j=1}^{N} \sum_{l=m-2 \mathcal{M}}^{m} L_{5+6(i-1), \quad 5+6(j-1)}^{m-l} \dot{\theta}_{j}^{l} \Delta t
$$

but the integral form is used hereafter as it is more compact.

Vertical forces are defined by:

$V_{i}=V_{D 3+6(i-1)}$

$-\sum_{j=1}^{N} A^{\infty}{ }_{3+6(i-1), 5+6(j-1)} \cdot \ddot{\theta}_{j}-\sum_{j=1}^{N} \int_{-\infty}^{t} L_{3+6(i-1), 5+6(j-1)}(t-\tau) \dot{\theta}_{j}(\tau) d \tau$

$-\sum_{j=1}^{N} A_{3+6(i-1), 1+6(j-1)}^{\infty} . \ddot{x}_{j}-\sum_{j=1}^{N} \int_{-\infty}^{t} L_{3+6(i-1), 1+6(j-1)}(t-\tau) \dot{x}_{j}(\tau) d \tau$ 
$-\sum_{j=1}^{N} A^{\infty}{ }_{3+6(i-1), 3+6(j-1)} \cdot \ddot{z}_{j}-\sum_{j=1}^{N} \int_{-\infty}^{t} L_{3+6(i-1), 3+6(j-1)}(t-\tau) \dot{z}_{j}(\tau) d \tau$

$+V_{\text {rest } i}+V_{\text {drag } i}+V_{\text {mean } i}$

longitudinal horizontal forces are defined by:

$H_{i}=H_{D 1+6(i-1)}$

$-\sum_{j=1}^{N} A_{1+6(i-1), 5+6(j-1)}^{\infty} . \ddot{\theta}_{j}-\sum_{j=1}^{N} \int_{-\infty}^{t} L_{1+6(i-1), 5+6(j-1)}(t-\tau) \dot{\theta}_{j}(\tau) d \tau$

$-\sum_{j=1}^{N} A_{1+6(i-1), 1+6(j-1)}^{\infty} \cdot \ddot{x}_{j}-\sum_{j=1}^{N} \int_{-\infty}^{t} L_{1+6(i-1), 1+6(j-1)}(t-\tau) \dot{x}_{j}(\tau) d \tau$

$-\sum_{j=1}^{N} A_{1+6(i-1), 3+6(j-1)}^{\infty} . \ddot{z}_{j}-\sum_{j=1}^{N} \int_{-\infty}^{t} L_{1+6(i-1), 3+6(j-1)}(t-\tau) \dot{z}_{j}(\tau) d \tau$

$+H_{\text {drag } i}+H_{\text {mean } i}$

The restoring heave force and pitch moment for a single float are given by: $V_{r e s t}=-\rho g \pi r^{2} z$ and $M_{\text {rest }}=-\rho g \pi \frac{r^{4}}{4} \theta$, where $r$ is float radius $\left(H_{\text {rest }}=0\right)$. The drag forces are given by $H_{\text {drag } i}=$ $-0.5 \rho A_{i} C_{D}\left|\dot{x}_{l}\right| \dot{x}_{l}, V_{\text {drag } i}=-0.5 \rho \pi r_{i}^{2} C_{D}\left|\dot{z}_{1}\right| \dot{z}_{1}$, and $M_{\text {drag } i}=-V_{\text {drag } i} h_{i}-H_{\text {drag } i} v_{i} . A_{i}$

is the vertical submerged frontal area for a float. Note float velocity relative to flow velocity is not considered and drag coefficient $C_{D}$ is effectively a viscous tuning parameter which is large for damping plates.

The wind thrust is given by

$H_{\text {wind }}=0.5 \rho_{\text {air }} A_{\text {turb }} C_{T}\left(U_{\text {hub }}-\dot{x}_{\text {hub }}\right)^{2}$

where $U_{h u b}$ is wind speed at the hub, $\dot{x}_{h u b}$ is hub velocity, $\rho_{\text {air }}$ is air density and $A_{\text {turb }}$ is the swept area for the rotor of radius $r_{\text {turb }}, \pi r_{\text {turb }}^{2}$. The thrust coefficient $C_{T}$ is dependent on the wind speed and is determined from blade element momentum theory using the NREL $5 \mathrm{MW}$ turbine characteristics [16]. The force is assumed to be quasi steady and defined by the relative velocity $\left(U_{h u b}-\dot{x}_{h u b}\right)$; note the rotation speed is also dependent on wind speed. The quasi-steady behaviour has been shown to be a close approximation for marine turbines in currents and waves where the flow velocity is almost uniform and wave period is greater than about $6 \mathrm{~s}[1]$ and the 
same principles apply to wind turbines. The $C_{T} v U_{\text {hub }}$ curve is shown in Fig. 3 with cut out of $25 \mathrm{~m} / \mathrm{s}$ (at full scale). Above this value the turbine is parked;

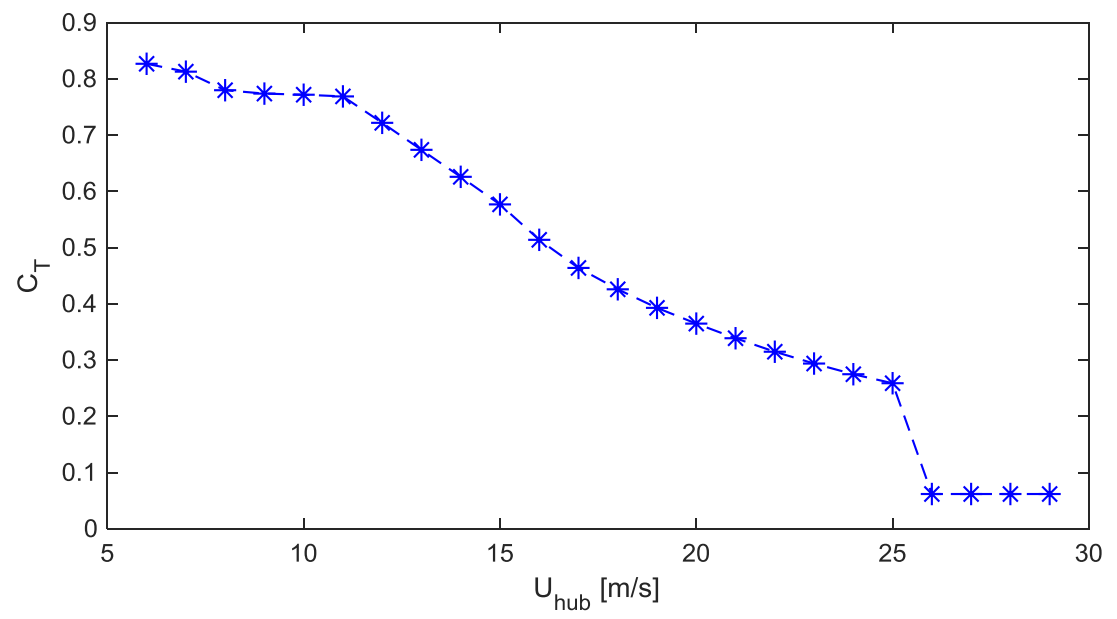

Fig.3 Variation of thrust coefficient $C_{T}$ with full scale wind speed at hub $U_{\text {hub }}$

it is also parked below the cut in of $3 \mathrm{~m} / \mathrm{s}$ but this is not relevant here. For the purposes of this demonstration the wind velocity at the hub is assumed uniform across the swept area. The moment about $\mathrm{O}$ in Eqs.1, 8 is $M_{\text {wind }}=-v_{\text {hub }} H_{\text {wind }}$.

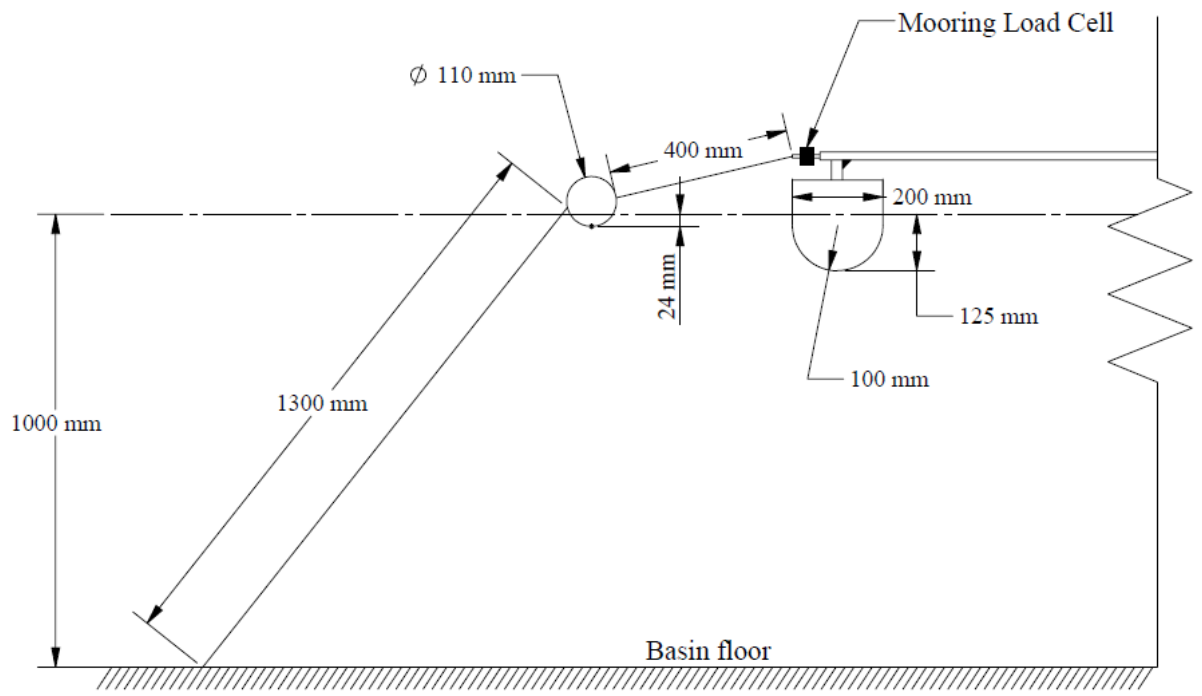

Fig.4 Diagram of mooring lines in still water in just taut condition 


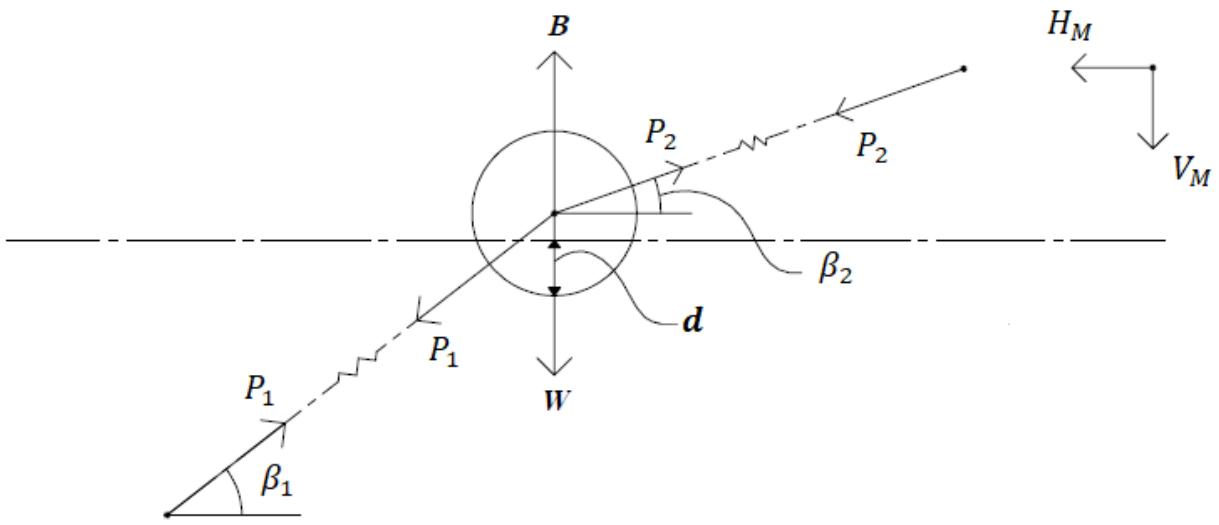

Fig.5 Diagram of mooring forces

The mooring lines are shown in Fig.4 in still water with the small spherical buoy of $0.11 \mathrm{~m}$ diameter and mass $87 \mathrm{~g}$. It is assumed that the buoy is subject only to buoyancy force $B$, weight $W$ and mooring forces $H_{M}$ and $V_{M}$, shown in the force diagram in Fig.5. The submerged depth $d$ in still water is $0.024 \mathrm{~m}$, shown in Fig.5. The mooring lines are effectively inextensible although small damping may be added in the model for extreme motions. When the lines are taut the forces are shown in Fig.5 with $P$ for tension force

$H_{M}=P_{2} \cos \left(\beta_{2}\right)$

$V_{M}=P_{2} \sin \left(\beta_{2}\right)$

At the buoy in the horizontal direction

$P_{2} \cos \left(\beta_{2}\right)=P_{1} \cos \left(\beta_{1}\right)=H_{M}$

And in the vertical

$B-W=P_{1} \sin \left(\beta_{1}\right)-P_{2} \sin \left(\beta_{2}\right)=H_{M}\left(\tan \left(\beta_{1}\right)-\tan \left(\beta_{2}\right)\right)$

giving

$H_{M}=(B-W) /\left(\tan \left(\beta_{1}\right)-\tan \left(\beta_{2}\right)\right)$

and hence $V_{M}$. The position of bow float $1\left(x_{1}, z_{1}\right)$ is known at each time level. We now define position of mooring connection relative to bed connection point as $x_{1 b}, z_{1 b}$, and when tension is just zero as $x_{1 b 0}, z_{1 b 0}$. If length of lines (to sphere centre) are $l_{1}$ and $l_{2}$ then

$l_{1} \cos \left(\beta_{1}\right)+l_{2} \cos \left(\beta_{2}\right)=x_{b 1}$

$l_{1} \sin \left(\beta_{1}\right)+l_{2} \sin \left(\beta_{2}\right)=z_{b 1}$

$\beta_{1}, \beta_{2}$ may thus be determined which defines submergence $d$ and hence $B$ and $H_{M}$ and $V_{M}$. The line is slack if $x_{1 b}<x_{1 b 0}$ and $H_{M}=V_{M}=0$. The submergence $d$ is determined by the vertical position of the buoy relative to the bed $l_{1} \sin \left(\beta_{1}\right)$ and $\Delta d=l_{1}\left(\sin \left(\beta_{10}\right)-\sin \left(\beta_{1}\right)\right)$. 
and when fully submerged

$d>2 r \quad B=4 \rho g \pi \frac{r^{3}}{3}$

The equations were advanced in time using Beeman's method with time step $\Delta t$

$\theta^{n+1}=\theta^{n}+\dot{\theta}^{n} \Delta t+\ddot{\theta}^{n} \Delta t^{2} / 2$

$\dot{\theta}^{n+1}=\dot{\theta}^{n}+\ddot{\theta}^{n} \Delta t$

$x_{O}^{n+1}=x_{O}^{n}+\dot{x}_{O}^{n} \Delta t+\ddot{x}_{O}^{n} \Delta t^{2} / 2$

$z_{O}^{n+1}=z_{O}^{n}+\dot{z}_{O}^{n} \Delta t+\ddot{z}_{O}^{n} \Delta t^{2} / 2$

$\dot{x}_{O}^{n+1}=\dot{x}_{O}^{n}+\ddot{x}_{O}^{n} \Delta t$

$\dot{z}_{O}^{n+1}=\dot{z}_{O}^{n}+\ddot{z}_{O}^{n} \Delta t$

The WAMIT coefficients are for all cross coupled terms between floats as well as for the directly coupled (diagonal) terms which have greatest magnitude. There are thus $(3 N)^{2}$ non-zero coefficients for $N$ floats with 3 modes (heave, surge, pitch) for radiation damping and added mass and with $3 \mathrm{~N}$ coefficients for diffraction forces and mean forces. Forming a direct formulation for each of $\ddot{\theta}, \ddot{x}_{O}, \ddot{z}_{O}$ with all cross coupled terms would be tedious to generalise. However the dominant diagonal terms in added mass for each of $\ddot{\theta}, \ddot{x}_{O}, \ddot{z}_{O}$ may be removed from each of $H_{i}, V_{i}, M_{i}$ and added to the left hand side (LHS) of Eqs. 6,8,10 which was desirable for numerical stability. An iteration is still required with updated values of $\ddot{\theta}, \ddot{x}_{O}, \ddot{z}_{O}$ for terms on the RHS but this showed fast convergence with less than 10 iterations (default value). The radiation damping and diffraction force terms were not modified in the iteration. A time step size of $T_{p} / 200$ was sufficiently small to give converged results (to plotting accuracy).

The equation set with numerical solution is thus complete and proved stable and convergent.

\section{Wave basin configuration}

The experiments were undertaken in the Lir Ocean Basin of University College, Cork, Ireland with a curved line of 80 wave makers with sloping beaches on two sides as shown in Fig. 6. 


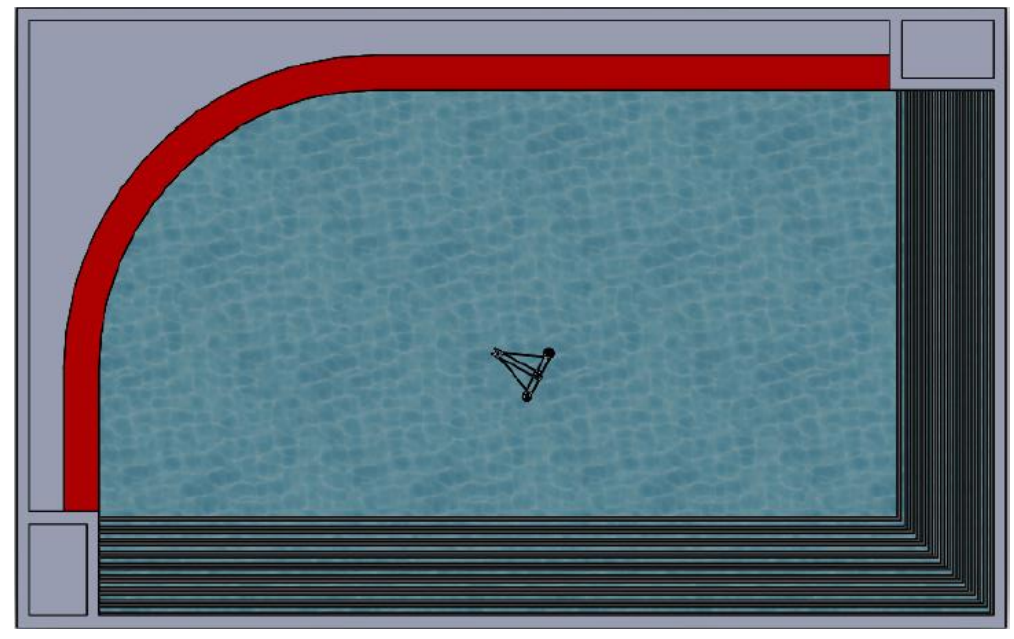

Fig.6 Plan view of Lir Ocean basin, approximately $25 \mathrm{~m} \times 15 \mathrm{~m}$, showing curved line of wave makers (red) and sloping beaches (black) with device in position.

An image of the device is shown in Fig.7.

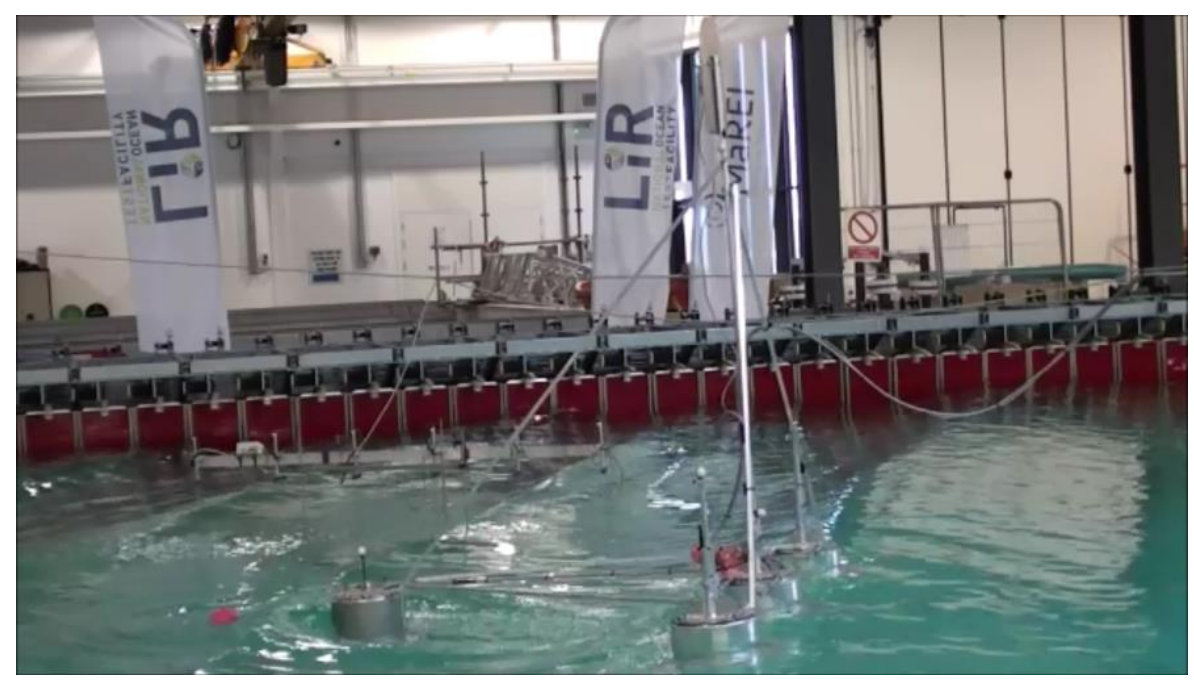

Fig.7 A video frame of the 4-float platform in the Lir ocean basin; note the red mooring buoy is partially submerged

The wave direction is at $63^{\circ}$ to the normal of the longer beach to minimise reflection which is considered to be less than $10 \%$ [4]. Since standard reflection analysis requires waves normal to a beach this was assessed by generating a group of regular waves (about 10). After their initial passage returning wave amplitudes were less than $10 \%$ of the original, having been reflected twice (or more) before returning to the working area. The device aligns naturally with the wave direction. Wave conditions (surface elevations) were measured by wave probes without the device in place and also by wave probes alongside the device. The following measurements were made at positions shown in Fig.2:

1. Acceleration at $\mathrm{O}$ just above deck on mid float (termed deck)

2. Acceleration at hub

3. Longitudinal mooring force on bow float 
The accelerometers were custom made, based on an Analog Devices ADXL335 (3-axis $\pm 3 g$ ) MEMS device coupled with a Texas Instruments XTR 116 current loop transmitter and the mooring load cell was a sub-miniature tension/compression cell with $50 \mathrm{~N}$ limit from Omega Engineering Ltd. The load cell was linear to within measuring accuracy and the accelerometer was inherently linear with a resolution close to 1:3000. The wave probes measured surface elevation with an error of less than 1 $\mathrm{mm}$. National Instruments data acquisition was used.

The mass and inertia of the floats and components are given in Table 2.

\begin{tabular}{|c|c|c|c|c|c|c|}
\hline & Mass $[\mathrm{kg}]$ & $x_{g}[\mathrm{~m}]$ & $y_{g}[\mathrm{~m}]$ & $z_{g}[\mathrm{~m}]$ & $\begin{array}{c}I_{x x} \\
{\left[\mathrm{kgm}^{2}\right]}\end{array}$ & $\begin{array}{c}I_{y y} \\
{\left[\mathrm{kgm}^{2}\right]}\end{array}$ \\
\hline Bow mass & 2.60 & -1.356 & 0 & -0.257 & 0.217 & 5.035 \\
\hline Bow ballast & 4.00 & -1.356 & 0 & -0.400 & 0.456 & 7.830 \\
\hline Bow plate & 0.96 & -1.355 & 0 & -0.330 & 0.163 & 1.932 \\
\hline Bow/mid beams & 2.467 & -0.456 & 0 & -0.071 & 0.292 & 1.069 \\
\hline Mid float left & 2.833 & -0.027 & -0.699 & -0.175 & 1.525 & 0.140 \\
\hline plate & 0.96 & -0.027 & -0.699 & -0.323 & 0.580 & 0.110 \\
\hline Mid float centre & 2.740 & -0.027 & 0 & -0.184 & 0.135 & 0.137 \\
\hline Plate & 0.96 & -0.027 & 0 & -0.323 & 0.109 & 0.110 \\
\hline Mid float right & 2.833 & -0.027 & 0.699 & -0.175 & 1.525 & 0.149 \\
\hline Plate & 0.96 & -0.027 & 0.699 & -0.323 & 0.580 & 0.110 \\
\hline Turbine+support & 5.048 & -0.124 & 0.002 & 1.218 & 8.802 & 8.956 \\
\hline
\end{tabular}

Table 2 Mass of each component with centre of mass and inertia relative to 0 .

\section{Results}

The model has been defined in section 2 and empirical drag coefficients are required. [36] showed $C_{d}>4$ for heave and $C_{d} \approx 6$ was a representative value although dependent slightly on amplitude of motion. For heave $C_{d}=6$ is assumed and $C_{d}=0$ for surge since the horizontal cross section of each float is circular and zero proved effective for WEC simulations with rounded base floats; CFD also showed drag coefficient was very small [11]. [36] also produced a simple formula for added mass in heave and that obtained from WAMIT was within $1 \%$ providing a useful cross check.

\section{Hydrodynamic only tests}

The variation of rms hub and deck acceleration (accn) with peak period $T_{p}$ is shown in Figs. 8 and 9 respectively for $H_{s} \approx 0.04-0.06 \mathrm{~m}$ from experiment, model with mooring (termed full) and model without mooring (termed linear). The $H_{s}$ values associated with each $T_{p}$ are given in Table 3.

\begin{tabular}{|c|l|l|l|l|l|l|l|l|l|l|}
\hline$T_{p}(s)$ & 0.7 & 0.8 & 0.9 & 1.0 & 1.1 & 1.2 & 1.4 & 1.6 & 1.8 & 2.0 \\
\hline$H_{S}(m)$ & 0.042 & 0.049 & 0.054 & 0.057 & 0.057 & 0.059 & 0.057 & 0.056 & 0.057 & 0.062 \\
\hline
\end{tabular}

Table 3 Wave definition for $H_{s} \approx 0.04-0.06 m$ with $\gamma=3.3$

The mooring has little effect and experimental measurements are similar. 


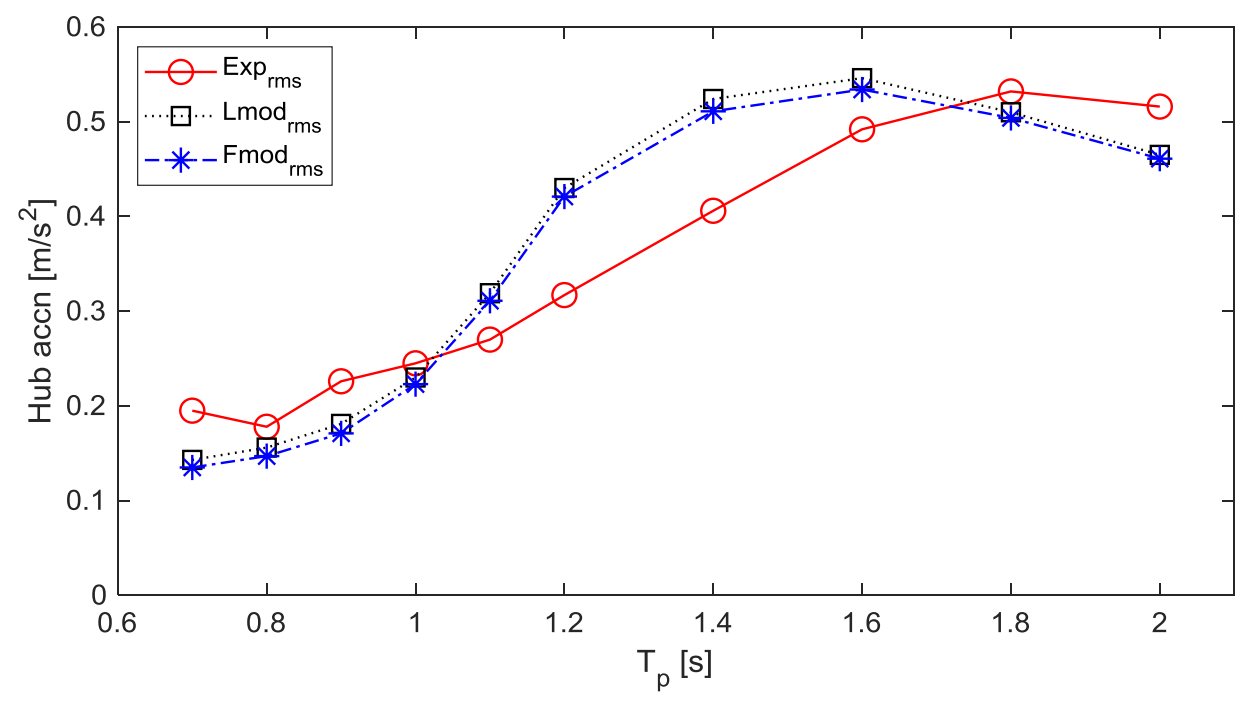

Fig.8 Variation of rms hub acceleration with $T_{p}$ from experiment (Exp), Linear only model (Lmod) and full model with mooring (Fmod)

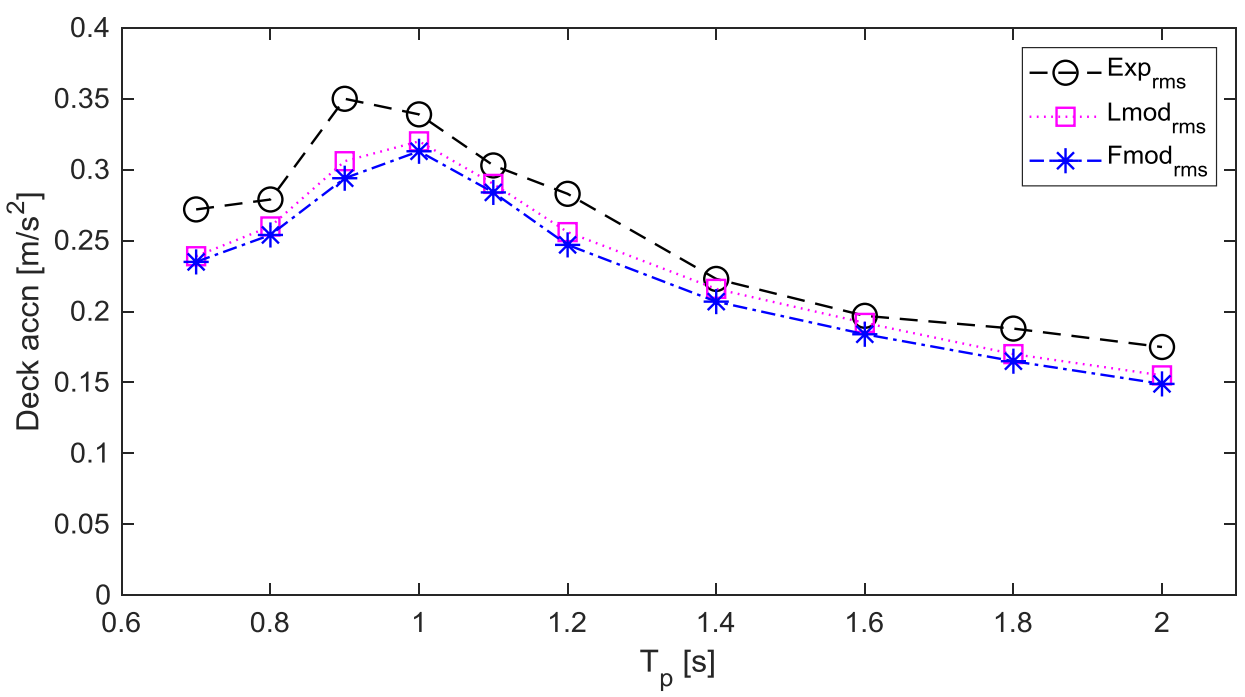

Fig.9 Variation of rms deck acceleration with $T_{p}$ from experiment (Exp), Linear only model (Lmod) and full model with mooring (Fmod)

Fig. 10 shows the variation of mean force, due to zero-difference components, damping and their sum, with $T_{p}$ and the experimental mean force, equal to the mean mooring force. 


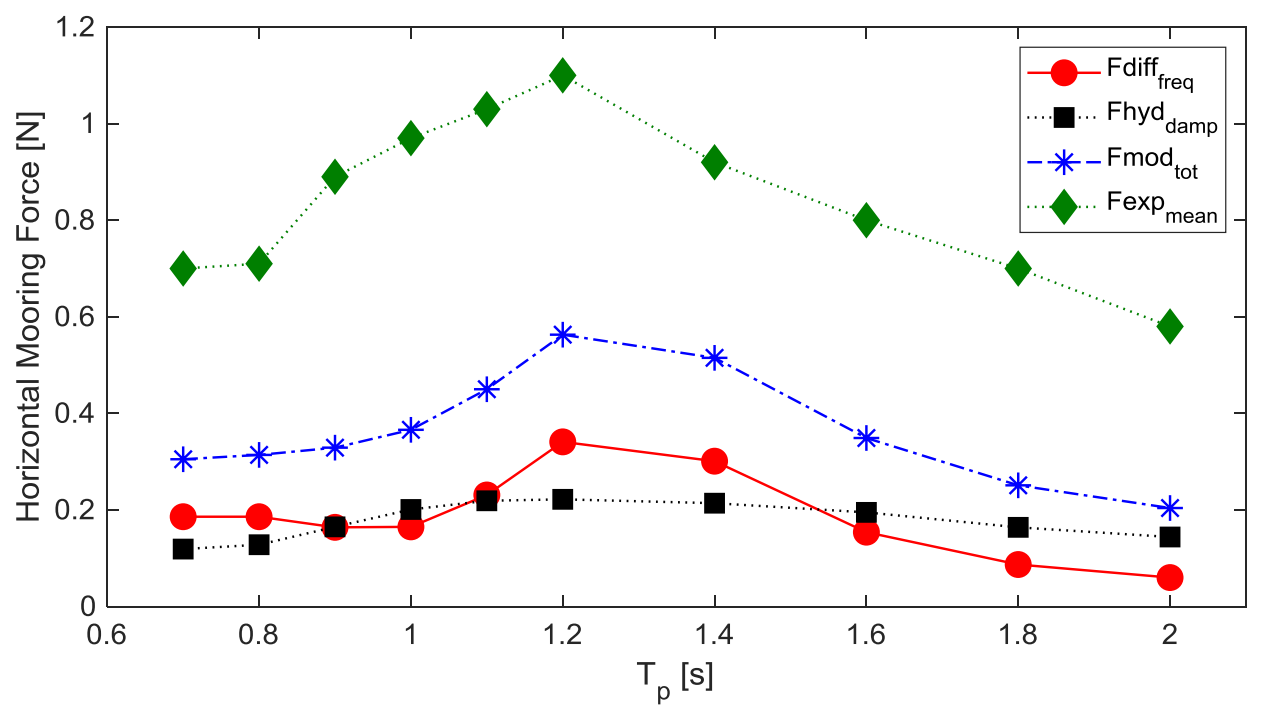

Fig.10 Variation of mean horizontal mooring force with $T_{p}$ due to zero-difference components in model (Fdiff), damping from radiation and drag (Fhyd), their sum (Fmod) and experiment (Fexp).

The model force is always less than that measured, less than half, suggesting that there is another component missing from the model. It may be conjectured that this is in part due to the mean drag due to wave induced currents which can be significant though not generally taken into account (discussed later). The experimental mean force is included with the mooring model and maximum acceleration for hub and deck $v T_{p}$ are shown in Figs. 11 and 12 respectively with experimental values.

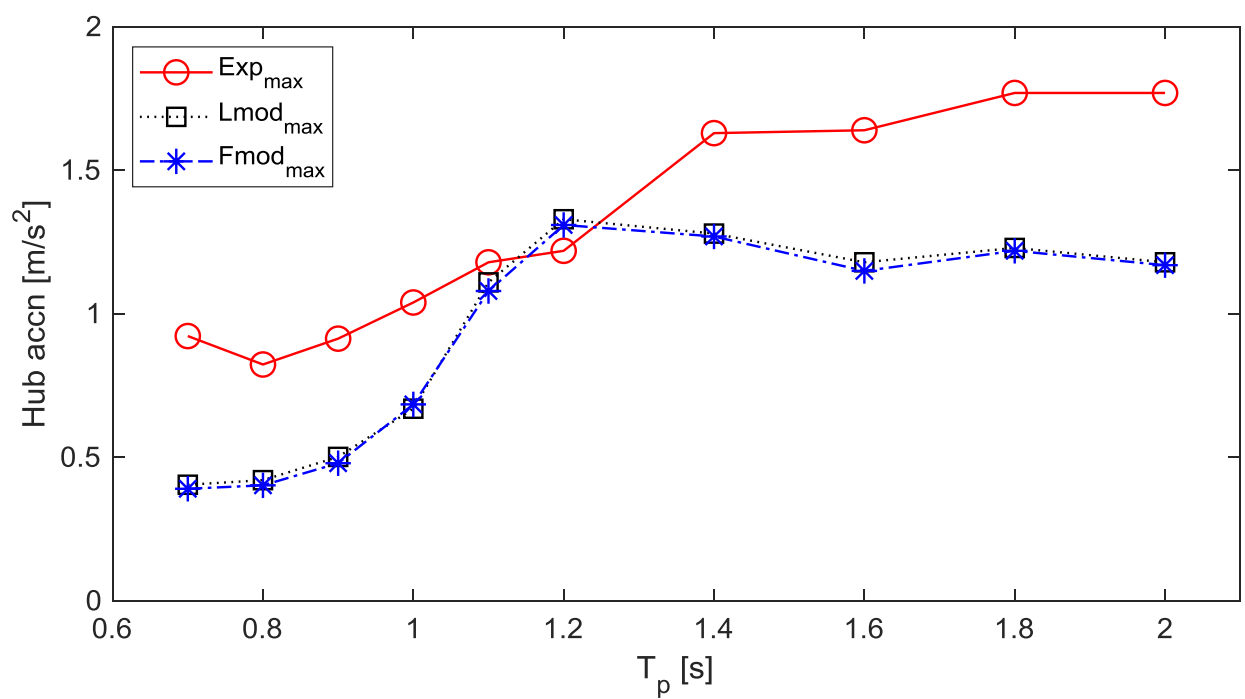

Fig.11 Variation of maximum hub acceleration with $T_{p}$ from experiment (Exp), Linear only model (Lmod) and full model with mooring (Fmod) 


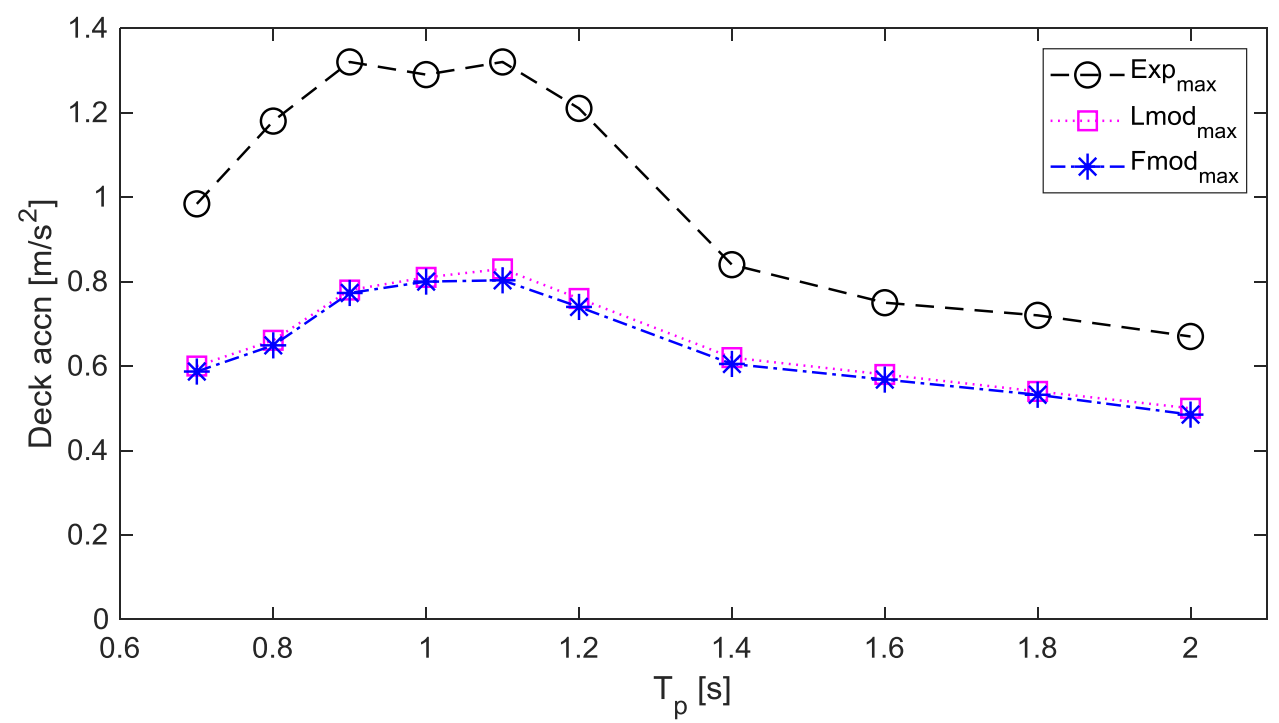

Fig.12 Variation of maximum deck acceleration with $T_{p}$ from experiment (Exp), Linear only model (Lmod) and full model with mooring (Fmod)

While the rms accelerations are similar, the maximum values are generally underestimated. Examples of spectra will show that model and experiment are also similar. The corresponding variations of maximum force with $T_{p}$ are shown in Fig. 13 with experimental values and model values are less than those measured.

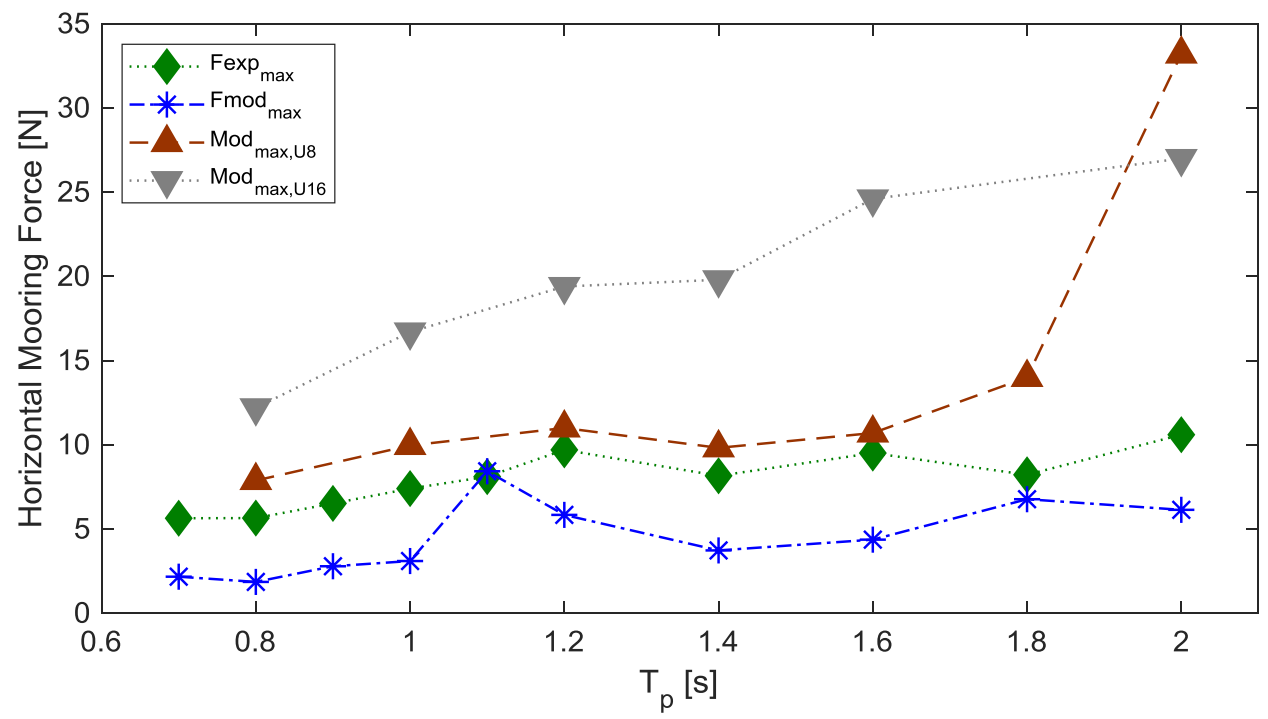

Fig.13 Variation of maximum horizontal force with $T_{p}$ from experiment (Exp), model with mooring (Fmod) and with wind speeds of 8 and $16 \mathrm{~m} / \mathrm{s}$ (full scale).

Tests were also made varying $H_{s}$ up to the largest possible in the basin for $T_{p}=1.0,1.4$ and $2.0 \mathrm{~s}$. Results for rms hub and deck acceleration are shown in Figs. 14 and 15 respectively. 


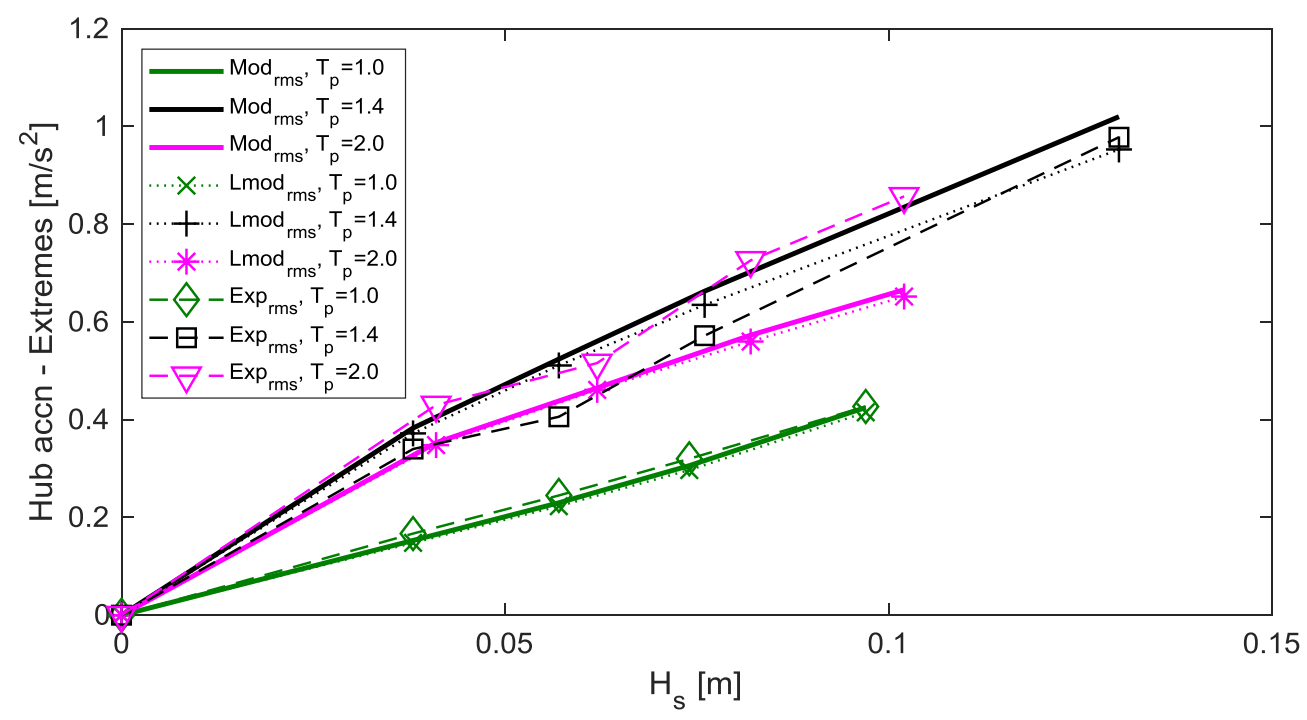

Fig.14 Variation of rms hub acceleration with $H_{s}$ for $T_{p}=1.0,1.4$ and $2.0 \mathrm{~s}$ for experiment (Exp), linear model only (Lmod) and full model with mooring (Mod)

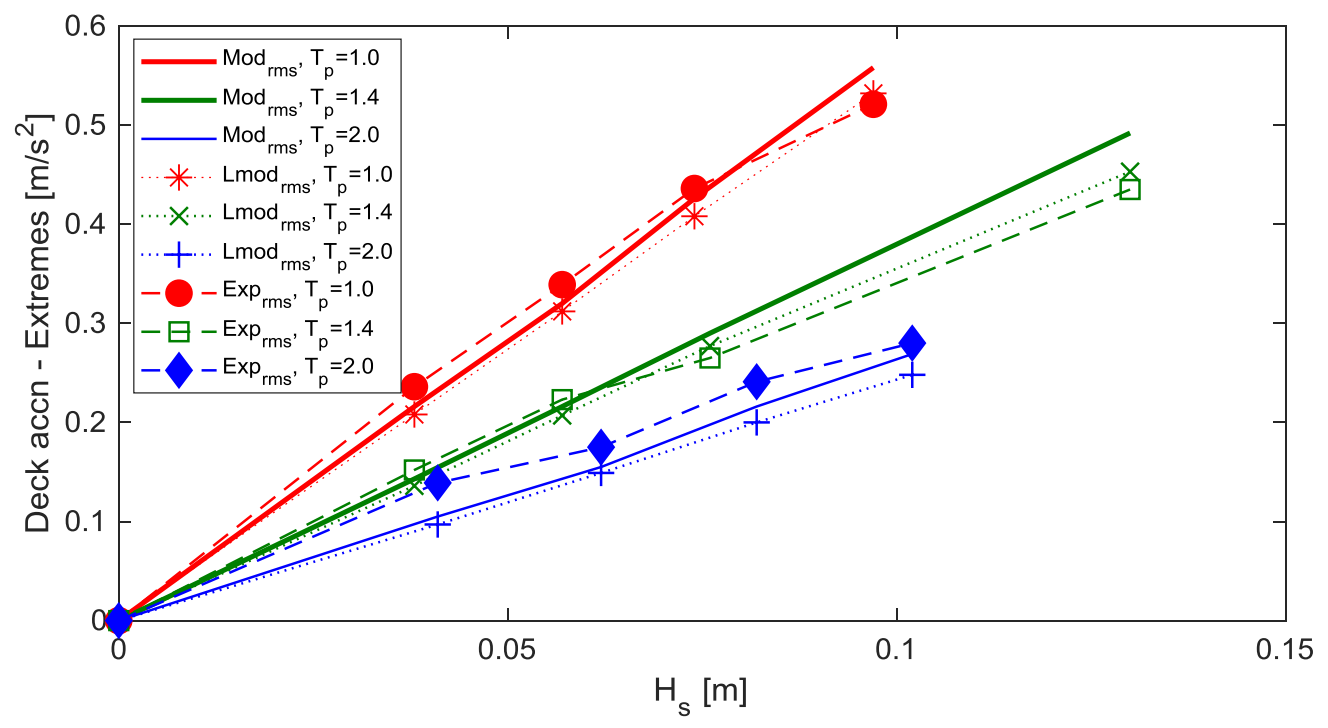

Fig.15 Variation of rms deck acceleration with $H_{s}$ for $T_{p}=1.0,1.4$ and $2.0 \mathrm{~s}$ for experiment (Exp), linear model only (Lmod) and full model with mooring (Mod)

The measured mean hydrodynamic forces are shown in Fig.16. These are used in the full model and maximum values are compared with experimental values, also in Fig.16. The model values are about half the experimental values as in previous cases. 


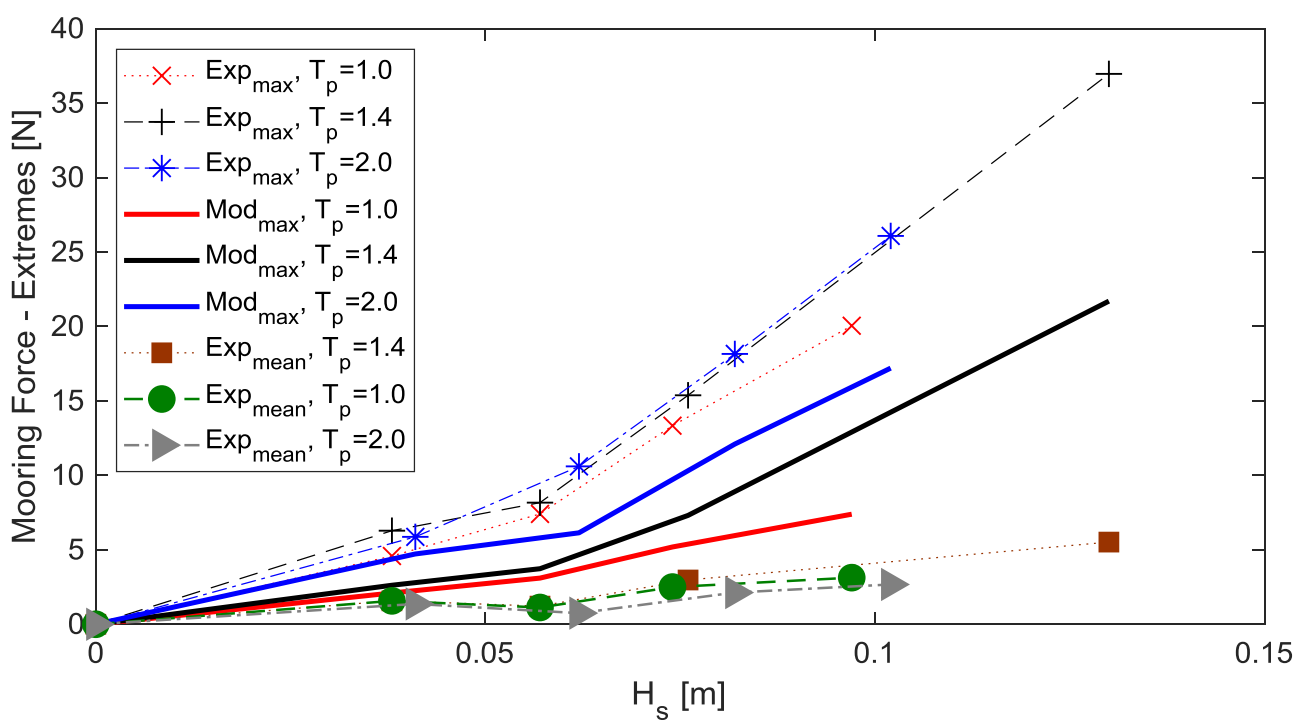

Fig.16 Variation of mooring force with $H_{s}$ for $T_{p}=1.0,1.4$ and $2.0 \mathrm{~s}$ : mean from experiment (Exp), maximum from experiment (Exp) and maximum from model (Mod)

The maximum hub and deck accelerations are shown in Figs. 17 and 18 respectively and the model underestimates as before; the linear only model gives very similar results as the full model with mooring.

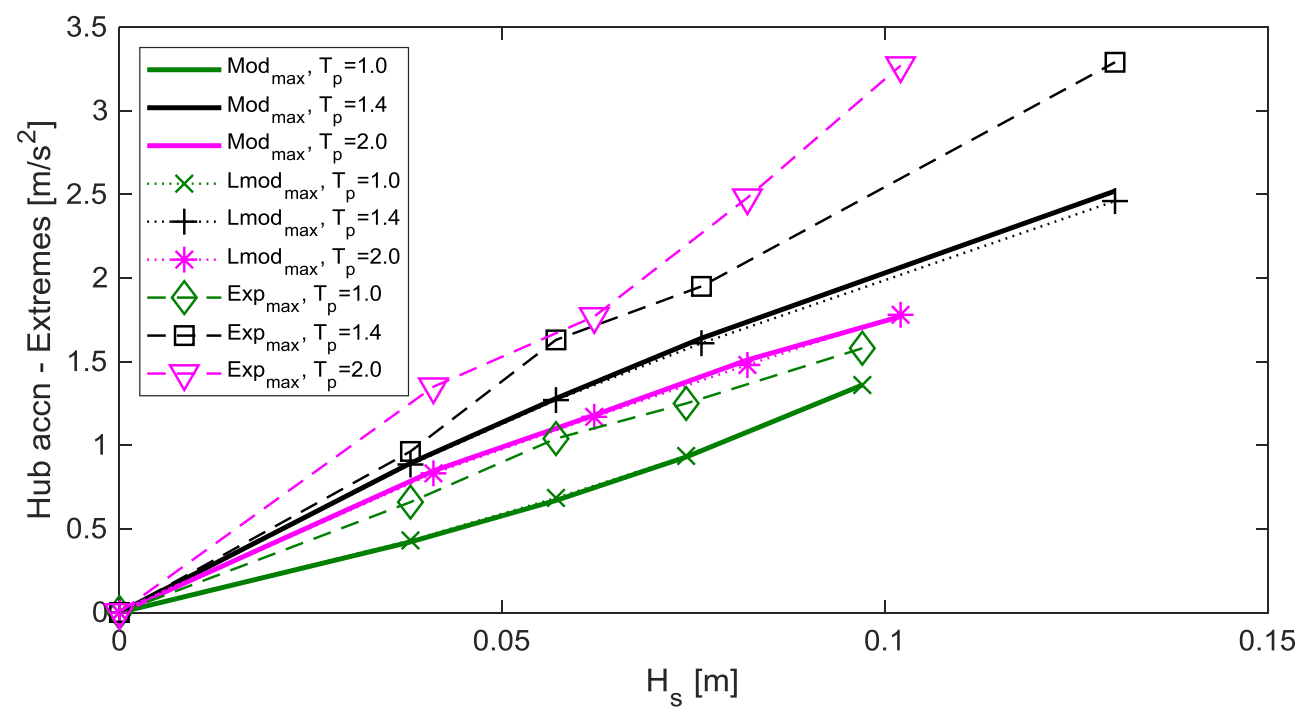

Fig.17 Variation of maximum hub acceleration with $H_{s}$ for $T_{p}=1.0,1.4$ and $2.0 \mathrm{~s}$ for experiment (Exp), linear model only (Lmod) and full model with mooring (Mod) 


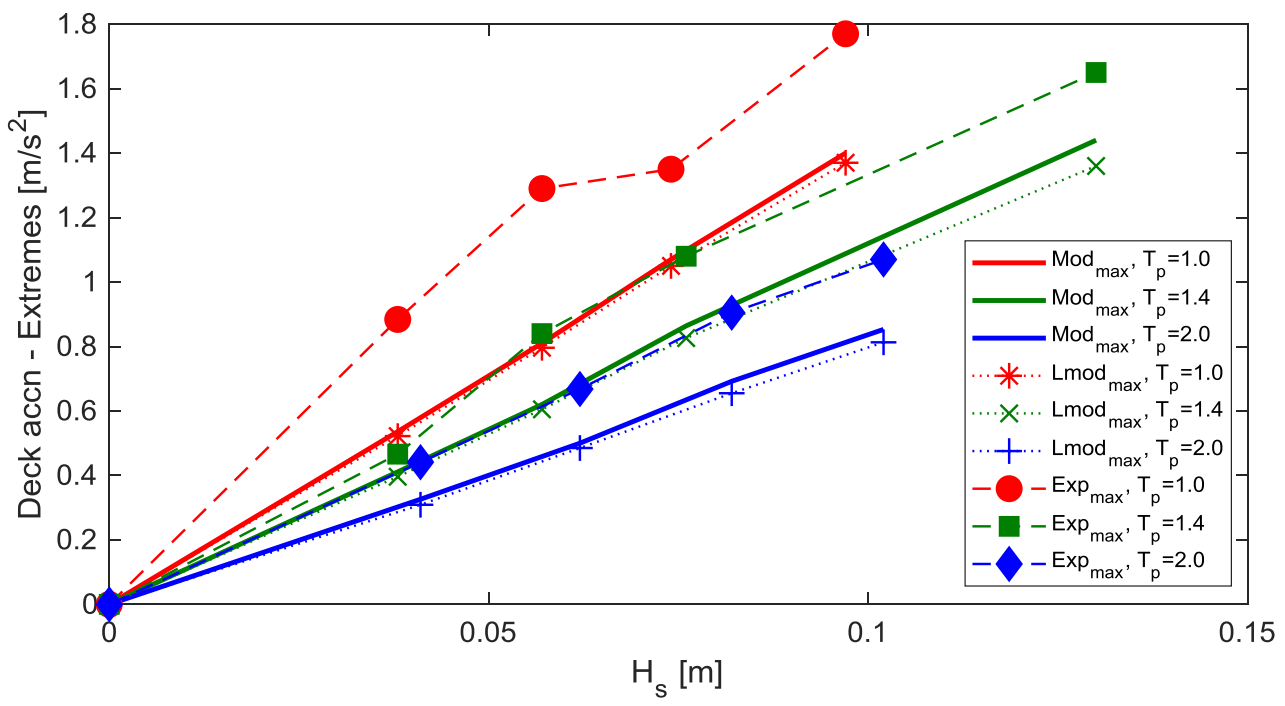

Fig.18 Variation of maximum deck acceleration with $H_{s}$ for $T_{p}=1.0,1.4$ and $2.0 \mathrm{~s}$ for experiment (Exp), linear model only (Lmod) and full model with mooring (Mod)

Spectra for acceleration and force show their degree of coupling and examples are shown with deck acceleration for the largest $H_{s}$ cases, for $T_{p}=1.0,1.4$ and $2.0 \mathrm{~s}$ in Fig.19. The form of the acceleration spectra predicted is quite similar to that measured although the peaks are underestimated. Note that there is occasional wave breaking for these cases. The force spectra are dominated by the mean component with some content at the wave frequencies and lower frequencies but the acceleration spectra show negligible corresponding content at the lower frequencies, indicating a lack of coupling between motion and mooring dynamics. This is consistent with response being almost independent of mooring forces.

a)
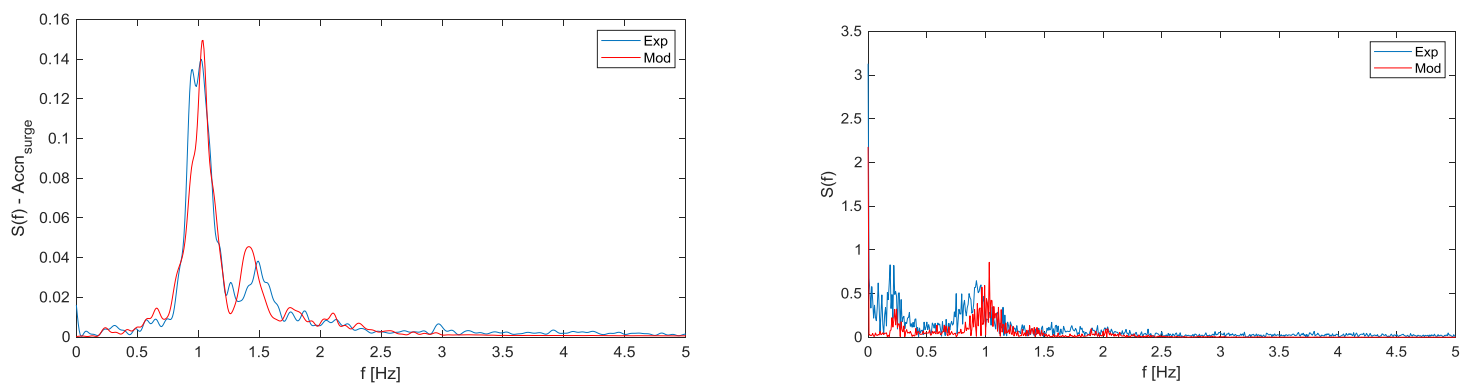

b)
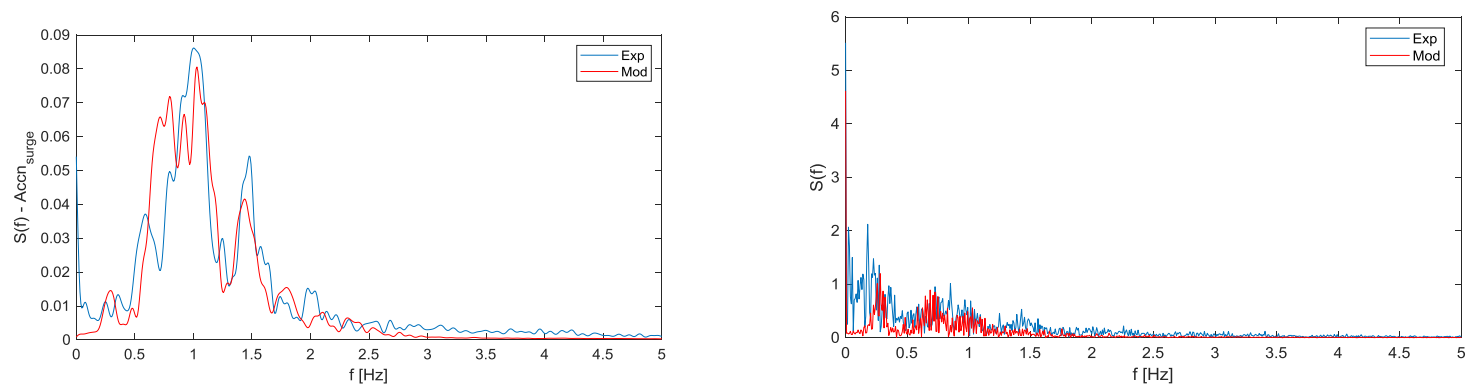

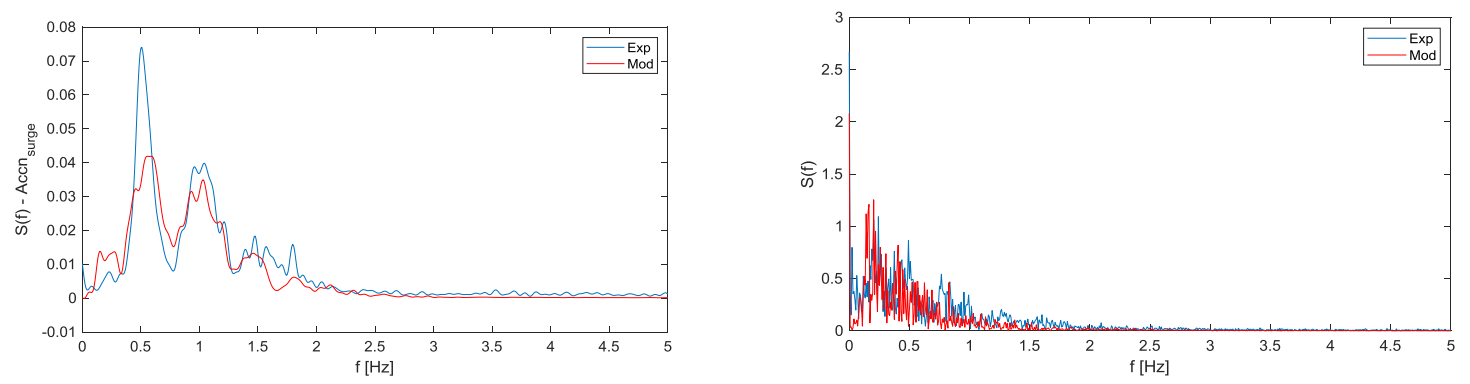

Fig. 19 Spectra of deck acceleration (LHS) and mooring force (RHS) for a) $T_{p}=1.0 \mathrm{~s}, H_{s}=0.097 \mathrm{~m} \mathrm{~b}$ ) $T_{p}$ $=1.4 \mathrm{~s}, H_{s}=0.130 \mathrm{~m}$ and c) $T_{p}=2.0 \mathrm{~s}, H_{s}=0.102 \mathrm{~m}$. Blue shows experiment and red model.

\section{Effect of wind}

Since the model predicts rms accelerations reasonably, the effect of wind may be investigated. Wind velocities $U_{10}$ of 8 and $16 \mathrm{~m} / \mathrm{s}$ at $10 \mathrm{~m}$ at full scale are considered and, with a typical wind profile exponent of 0.11 [14], gives velocities of 10.16 and $20.32 \mathrm{~m} / \mathrm{s}$ at hub height which determines thrust. These velocities are just below and well above rated. Variation of rms hub acceleration with $T_{p}$ are shown for $H_{s} \approx 0.04-0.06 \mathrm{~m}$ in Fig. 20 for $U_{10}=0,1.13,2.26 \mathrm{~m} / \mathrm{s}$ at lab scale and the mean thrusts are respectively $0,4.77$ and $8.81 \mathrm{~N}$ which determines the mooring force. There is little effect with $U_{10}=8 \mathrm{~m} / \mathrm{s}$ but accelerations are slightly increased with $U_{10}=16 \mathrm{~m} / \mathrm{s}$. There are similar effects for rms deck accelerations shown in Fig. 21 although in this case $U_{10}=8 \mathrm{~m} / \mathrm{s}$ increases magnitude over that for zero wind speed.

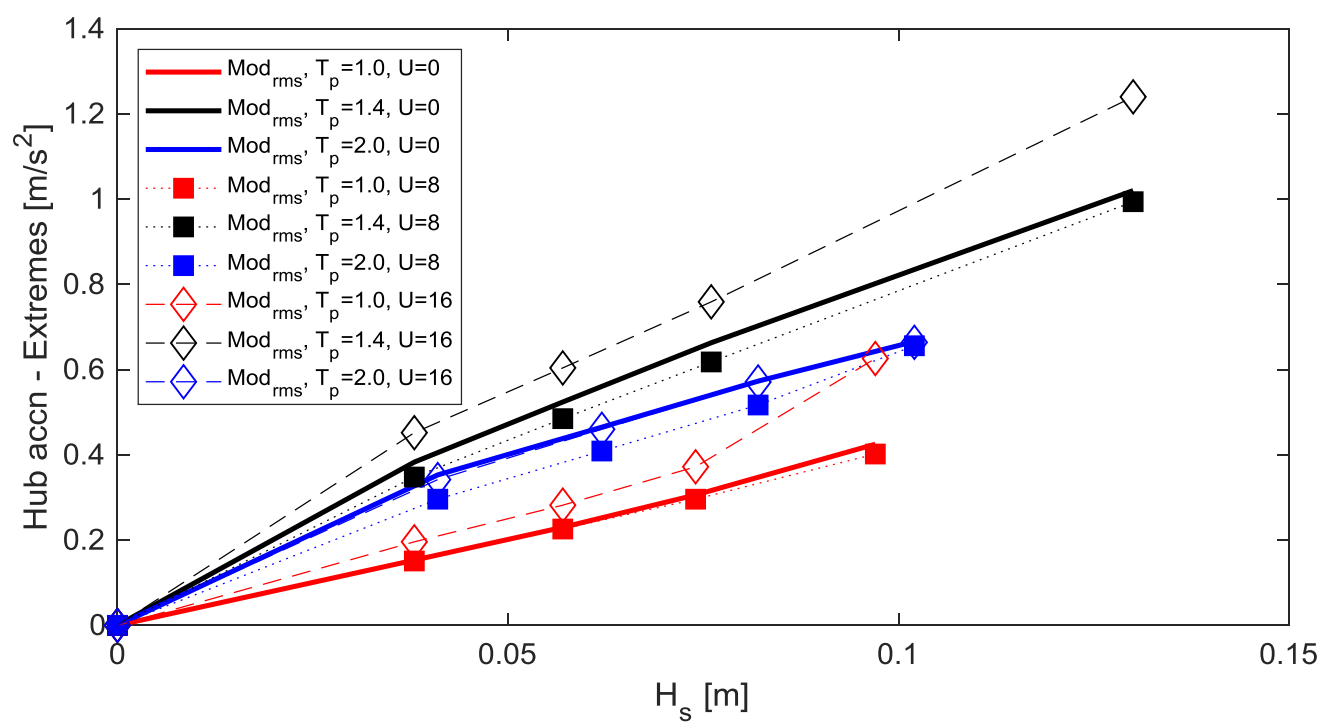

Fig.20 Variation of rms hub acceleration with $H_{s}$ for $T_{p}=1.0,1.4$ and $2.0 \mathrm{~s}$ from model for $U_{10}=0,8$, $16 \mathrm{~m} / \mathrm{s}$ (full scale) 


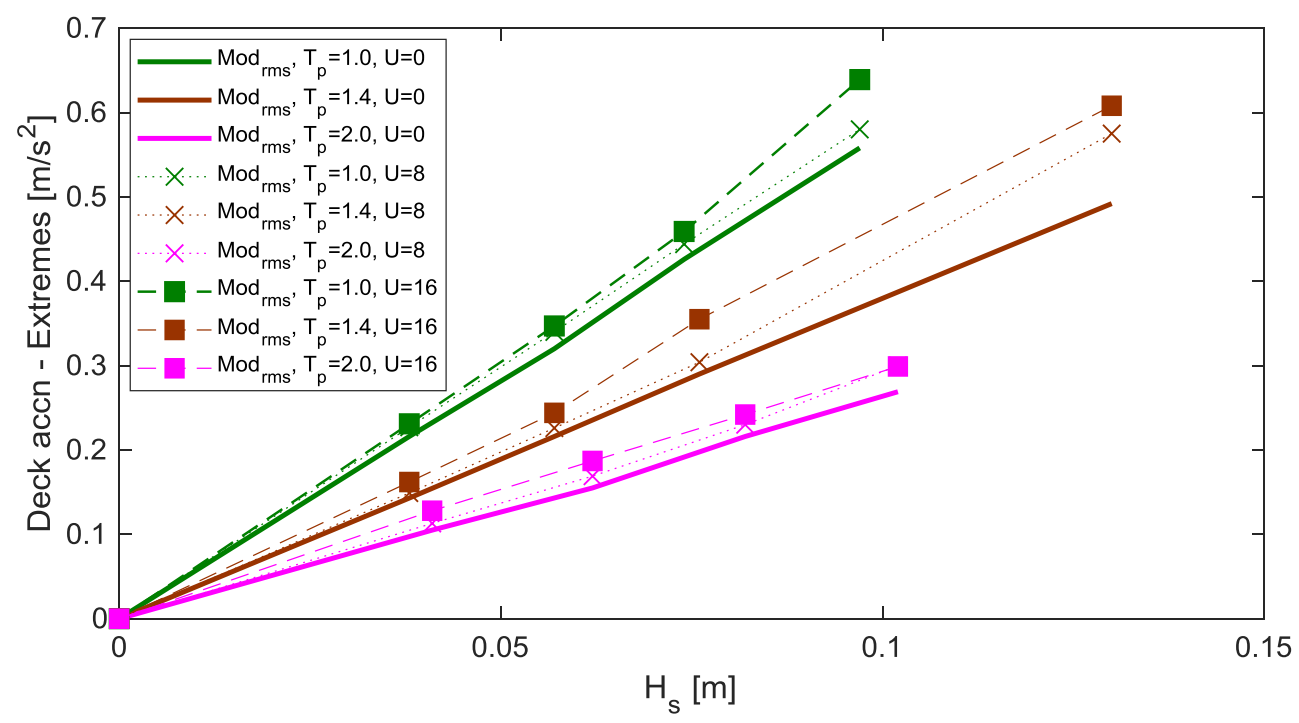

Fig.21 Variation of rms deck acceleration with $H_{s}$ for $T_{p}=1.0,1.4$ and $2.0 \mathrm{~s}$ from model for $U_{10}=0,8$, $16 \mathrm{~m} / \mathrm{s}$ (full scale)

Maximum hub and deck accelerations are shown in Figs. 22 and 23 and dependence on $U_{10}$ is similarly weak but it should be remembered that the model underestimated maxima for zero wind speed.

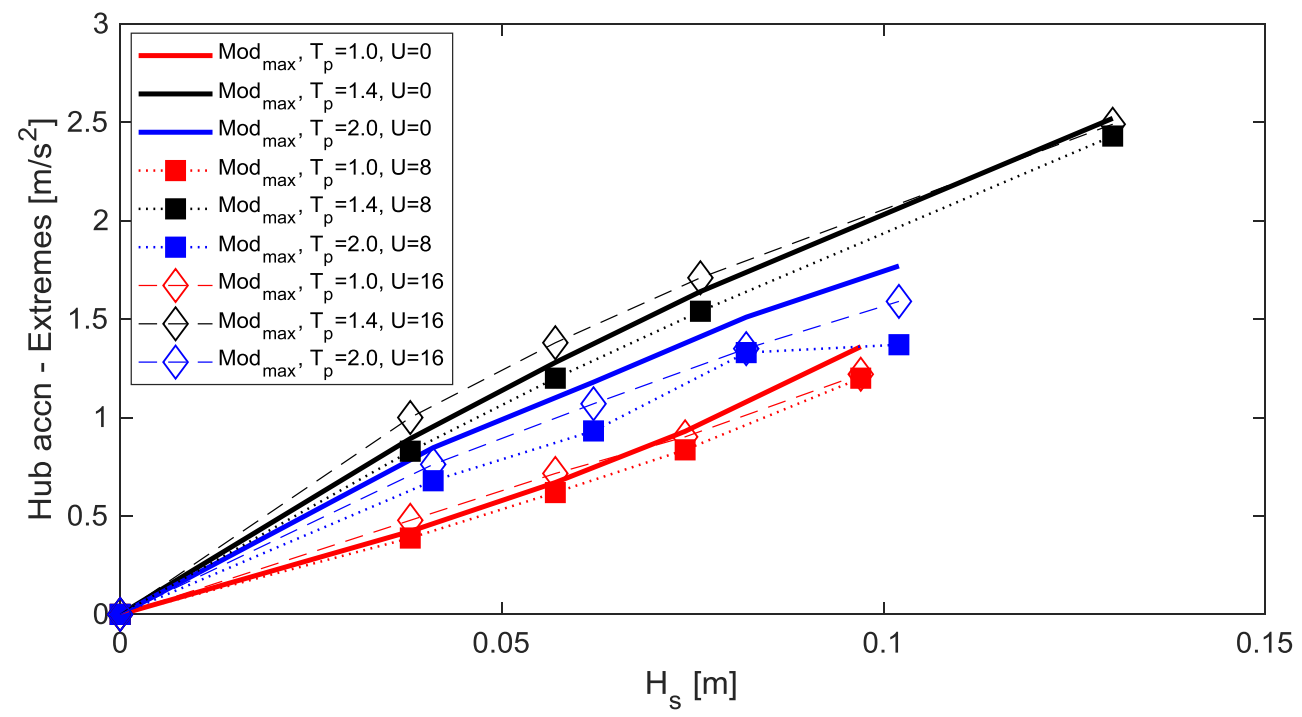

Fig.22 Variation of maximum hub acceleration with $H_{s}$ for $T_{p}=1.0,1.4$ and $2.0 \mathrm{~s}$ from model for $U_{10}=$ $0,8,16 \mathrm{~m} / \mathrm{s}$ (full scale) 


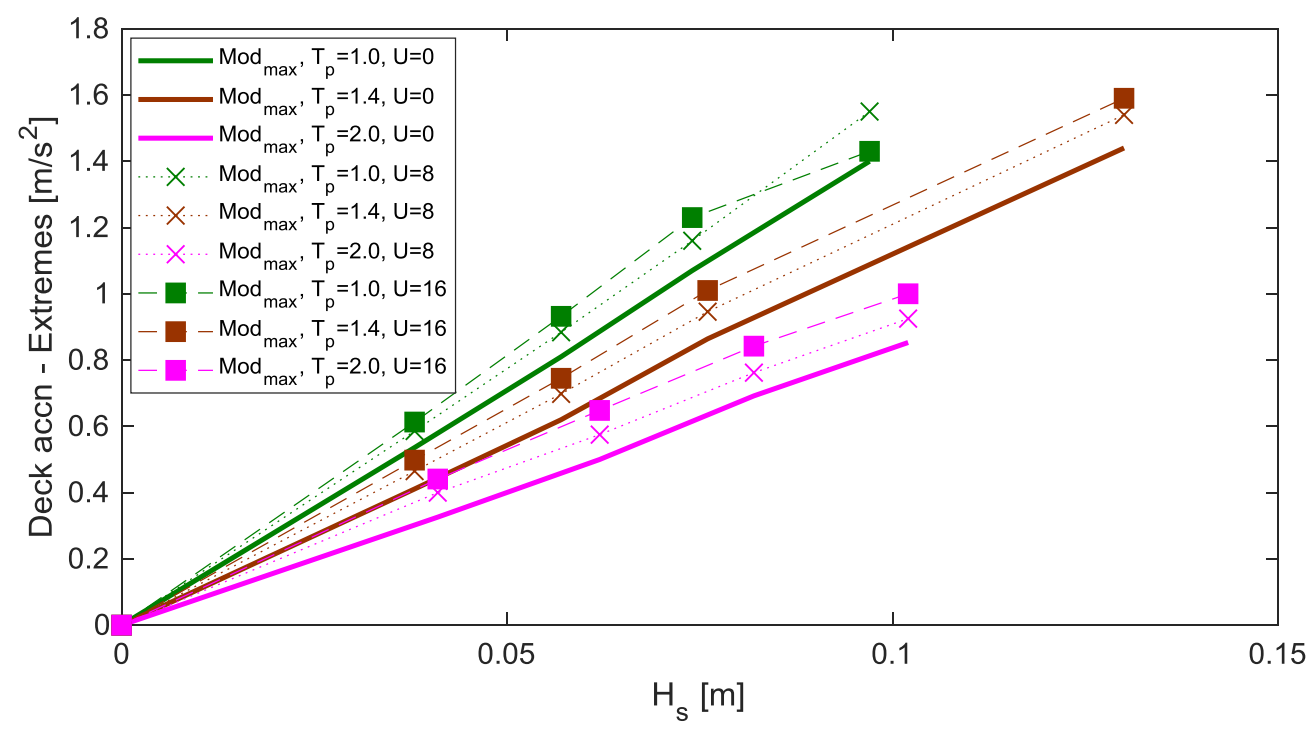

Fig.23 Variation of maximum deck acceleration with $H_{s}$ for $T_{p}=1.0,1.4$ and $2.0 \mathrm{~s}$ from model for $U_{10}=$ $0,8,16 \mathrm{~m} / \mathrm{s}$ (full scale)

The mean mooring forces are mainly due to the wind thrust in extreme conditions but the maxima are dominated by snatch loads and are not shown. Snatch loads occasionally occurred with zero wind speed. The snatch loads appear not to influence the prediction of accelerations by the model.

\section{Fully arisen sea states}

An important question is whether wave conditions impose limits on turbine operation in addition to normal cut in and cut out hub wind speeds. In a complete analysis for a given offshore site the range of wave conditions for each wind speed (typically in $1 \mathrm{~m} / \mathrm{s}$ bins) would be considered. The results above indicate that wind speed has little influence on hub accelerations for given wave conditions. To give some indication across a range of wind speeds, up to the maximum hub value of $25 \mathrm{~m} / \mathrm{s}$ for operation, we consider the 'fully arisen sea' often used in coastal engineering, where significant wave height and period are defined by wind speed for unlimited fetch such that in deep water $g H_{s} / U_{10}^{2}=0.283 ; g T_{s} / 2 \pi U_{10}=1.2$ [31]. With $T_{p}=1.058 T_{s}$ we simply have $T_{p}=0.813 U_{10}$ and $H_{s}=0.0282 U_{10}{ }^{2}$. The wave spectrum is Pierson-Moskowitz or JONSWAP with $\gamma=1$. The hub wind speed $U_{h u b}=1.27 U_{10}$. Fig. 24 shows the conditions for $U_{10}$ in range 8 to $20 \mathrm{~m} / \mathrm{s}$ (close to shut down). 


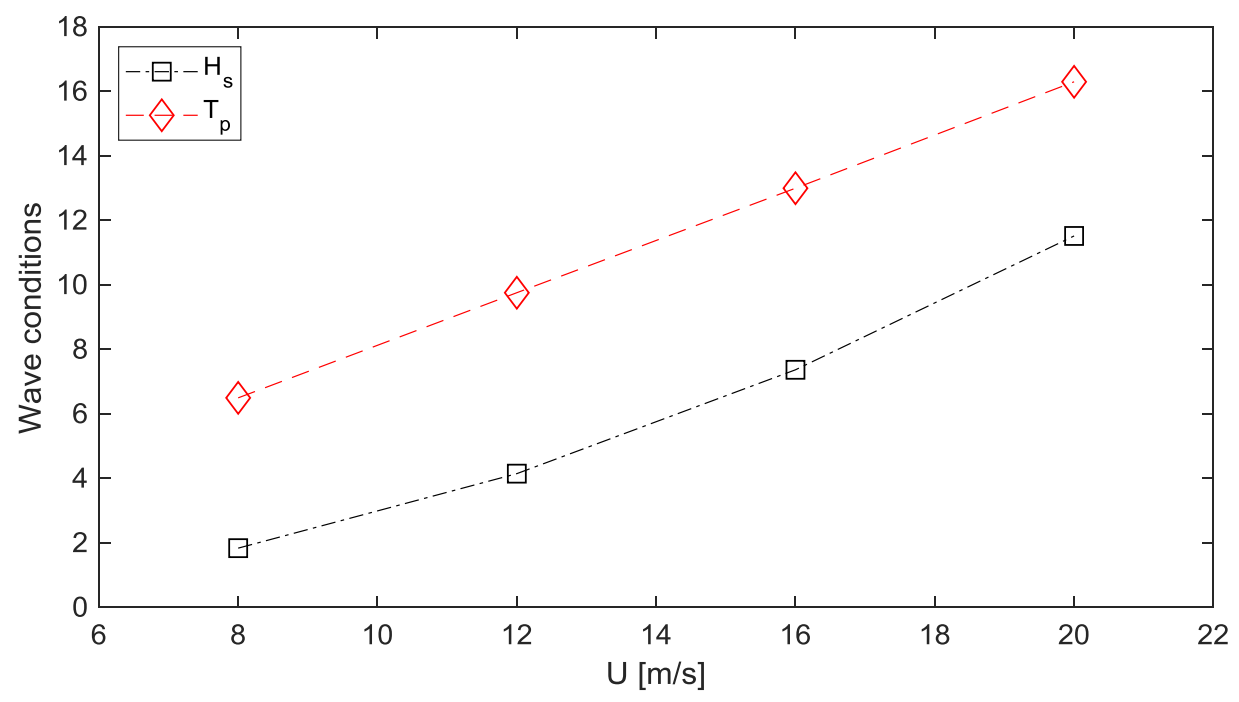

Fig.24 Dependence of $H_{s}$ and $T_{p}$ on wind speed $U$ at $10 \mathrm{~m}$ for fully arisen sea at full scale

The variation of rms and maximum hub and deck acceleration with $U_{10}$ are shown in Fig.25. The maximum accelerations are somewhat underestimated according to previous comparison with experiment and thus with $U_{10}=20 \mathrm{~m} / \mathrm{s}$ it is likely that the maximum hub acceleration will exceed 4 $\mathrm{m} / \mathrm{s}^{2}$; however this is not likely with $U_{10}=16 \mathrm{~m} / \mathrm{s}$. A shutdown with a hub speed of $20 \mathrm{~m} / \mathrm{s}$ rather than $25 \mathrm{~m} / \mathrm{s}$ may be necessary on this basis but this represents a minor loss of annual energy.

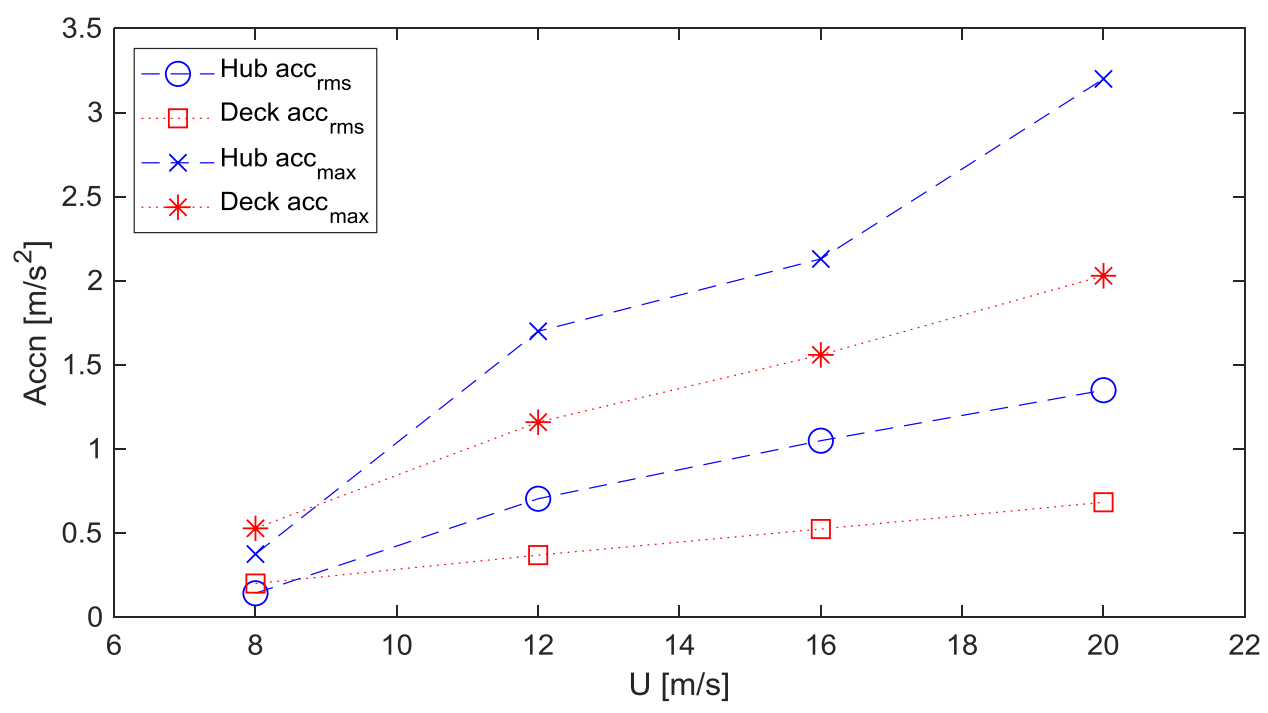

Fig. 25 variation of rms and maximum accelerations at hub and deck level with wind speed at $10 \mathrm{~m}$ for fully arisen sea at full scale

\section{Discussion}

A floating platform with damping plates in steep waves is complex hydrodynamically with nonlinear wave interactions and vortex shedding generating high drag. A complete computational fluid dynamics (CFD) simulation would require massive computer resources and even then may not produce reliable results. Linear diffraction analysis on the other hand is relatively efficient requiring order one minute on a laptop after hydrodynamic coefficients have been obtained, from WAMIT in 
this case. Empirical input is required to approximate drag forces but other nonlinear effects due to moorings are also omitted in the first instance and experimental validation is necessary. Although based on linear analysis, mean force estimates may be included in a time domain model. In addition to the mean force associated with zero difference frequencies which is standard, the mean force from energy flux absorbed due to radiation and drag is included here. Previously all components of difference and sum frequency effects have been included in frequency domain analysis with linearised drag and mooring forces, but not in the time domain to our knowledge. Although small, second-order forces of low frequency, due to difference frequency combinations, may excite response of low natural frequency due to a mooring restraint with little damping. Limiting secondorder forces to the mean is justified if frequency components do not excite motion with corresponding natural frequencies. If the response, acceleration in this case, and mooring force are uncoupled this will not occur and may be diagnosed from the spectra of motion and mooring force. For the slack-moored system of this study there was negligible response at low mooring frequencies and motion was only slightly affected by incorporating a mooring model. That accelerations are reasonably well predicted by linear diffraction modelling is consistent with results for the slack moored multi-float wave energy converter M4 where motion in extreme waves was also shown to be almost linear, in this case with rounded shapes and negligible drag since relative motion between floats is desirable to generate mechanical power [4, 29].

The results show that rms hub and deck accelerations are predicted reasonably with a physically realistic drag coefficient even in large waves. Although maximum or peak accelerations are somewhat underestimated, spectra are quite well reproduced. The mean mooring forces are also underestimated possibly because mean flow associated with wave-induced currents is not taken into account and are greatest near the water surface where the platform is situated. Based on measurements and analysis from [5] these currents would range from about 1-4 cm/s in the present tests where the underestimate of mean force is between 0.4 and $2.1 \mathrm{~N}$. Drag coefficients based on the submerged frontal area of all floats would be in the range 10 to 100 which does seem implausibly high. Peak mooring forces are also underpredicted, by a factor of about two. While nonlinearities are clearly responsible for underestimation of maxima it is not possible to identify the cause. There are nonlinear onset waves, the largest of which are breaking, variable surface elevations around each float affecting buoyancy (and hence restoring force) and Froude-Krylov forces and complex wake effects from damping plates. Such effects probably also contribute to the underestimation of mean forces, as well as wave-induced currents. Nevertheless the success in predicting rms acceleration without wind indicates that this may also be predicted with wind thrust effects which are simply defined by blade element momentum theory, including oscillation due to waves. This showed that accelerations are only slightly affected by wind. The simple thrust coefficient model may be replaced by a more general CFD model such as actuator line [1] which could account for wind shear and turbulence. By considering fully arisen seas only in the highest operational wind speeds is hub acceleration expected to be increased above $4 \mathrm{~m} / \mathrm{s}^{2}$ so wave action provides a further restriction on the operational envelope. However such an infrequent occurrence will have little influence on energy yield.

The importance of mean hydrodynamic force may be considered in relation to the mean wind thrust. At model scale the largest mean thrust would be $9.7 \mathrm{~N}$ (for the maximum full scale operating hub wind speed of $25 \mathrm{~m} / \mathrm{s}$ ) and this compares with the largest measured mean hydrodynamic force of $4.7 \mathrm{~N}$, obtained without wind loading. This is thus significant although smaller. On the other hand 
the maximum measured peak hydrodynamic force was $36 \mathrm{~N}$, again obtained without wind loading, which is much larger than the largest wind thrust. For such platforms reducing the peak mooring forces is of primary concern and a mooring design with catenary lines attached to the bow float could be considered.

The simple mooring model applied here is based on the buoyancy of the buoy relative to mean water level. For a relatively small floating body local surface elevation will modify buoyancy and there will additional effects due to Froude-Krylov, drag and added mass forces. The mooring model does however enable the influence of mooring dynamics on motion to be assessed and the mean mooring force is equal to the hydrodynamic force which may be compared with theory.

The general concept of a shallow draft semi-sub wind platform does seem viable in terms of acceptable motion for operation.

\section{Conclusions}

A slack-moored semi-submersible platform with relatively small draft has been proposed for supporting a wind turbine. The floater consists of four rigidly connected circular cylinders with damping plates to restrict motion and diameters as small as possible but large enough to provide buoyancy to support the wind turbine and column. Hydrodynamic only tests were undertaken in a wave basin and compared with time-domain linear diffraction modelling with the addition of empirical drag effects. rms accelerations at the turbine hub and just above deck were predicted approximately but maxima were somewhat underestimated. The mean force due to zero-difference wave frequency combinations was added (as is standard) and the mean force from energy flux required to balance radiation and drag damping was also added (not standard). This is possible because the platform motion is almost independent of mean force; the motion is effectively uncoupled from the mooring force. An equivalent process has previously been undertaken in the frequency domain requiring drag and mooring forces to be linearised, but this is not generally possible for highly nonlinear mooring and drag forces. The mean mooring forces are somewhat underestimated suggesting that additional nonlinear forces and mean flow effects due to waveinduced currents may be significant, which are not included in linear diffraction analysis. The maximum mooring forces are also underestimated and snatch loads can occur in both experiment and model for larger wave heights. The wind turbine thrust is added to the model based on a coefficient from blade element momentum theory. This coefficient is dependent on wind speed for a given turbine. The thrust is assumed to be quasi-steady, defined by a thrust coefficient based on the relative velocity at the hub. The accelerations show little dependence on wind speed for the range of experimental wave conditions and in extreme conditions the thrust is larger than the mean hydrodynamic mooring force from experiment (and model). Fully arisen sea conditions were also investigated by the model. For the cut out wind speed of $25 \mathrm{~m} / \mathrm{s}$ at hub level the maximum accelerations were estimated to be about $4 \mathrm{~m} / \mathrm{s}^{2}$ or more and probably unsuited for operation. For $20 \mathrm{~m} / \mathrm{s}$ or less accelerations were estimated to be below $4 \mathrm{~m} / \mathrm{s}^{2}$ and suitable for operation. Extreme wave conditions may thus limit operation although with a minor effect on annual energy yield. The mooring system was quite simple and primarily intended to prevent drift within the wave basin, with the floater attached to a single point mooring buoy tethered to the bed through light, effectively inextensible, cables. This design should be developed to avoid snatch loads, e.g. through greater mechanical damping and clump weights to provide more spring in the system, or by direct 
attachment of catenary mooring lines to the bow float. To simulate fully nonlinear effects on moorings CFD or SPH may be needed.

\section{Notation}

$a$ amplitude of wave component

$A$ added mass for each float from WAMIT, or float area

$B$ radiation damping for each float from WAMIT, or buoyancy force on mooring buoy

$c_{e}$ average wave speed for energy flux

$C_{d}$ drag coefficient

$d$ draft

$f \quad$ frequency

$h$ horizontal distance

$H$ horizontal force

$H_{S}$ significant wave height

$H_{M}$ horizontal mooring force

I moment of inertia

$l$ length mooring line

$L_{e}$ wave length based on energy period

$m$ mass

$M$ pitch moment

$N$ number of floats, $N_{m}$ number of masses

$P$ tension in mooring line

$r$ float radius

$S$ spectral density

$t$ time

$T_{p}$ peak period

$v$ vertical distance

$V$ vertical force

$V_{M}$ vertical mooring force 
$W$ weight mooring buoy

$x$ horizontal coordinate

$z$ vertical coordinate

$\beta$ angle mooring line

$\Delta t$ time step

$\gamma$ spectral peakedness factor in JONSWAP spectrum

$\theta$ angle

$\varphi$ phase

$\omega$ angular frequency

\section{Acknowledgements}

Support through the EU Marinet2 programme and the Energy Sustainability Conayct-SENER fund provided by the Mexican government is gratefully acknowledged.

\section{$\underline{\text { References }}$}

1. Apsley,D.D., Stallard,T. and Stansby,P.K. 2016 Actuator-line CFD modelling of tidal-stream turbines, 2nd International Conference on Offshore Renewable Energy (CORE2016), Glasgow, Scotland, 12-14 September.

2. Antonutti,R., Peyrard,C., Johanning,L., Incecik,A.,Ingram,D. 2014 An investigation of the effects of wind-induced inclination on floating wind turbine dynamics: heave plate excursion, Ocean Engineering, 91,208-217

3. Carbon Trust 2015 Floating Offshore Wind: Market and Technology Review, report for the Scottish Government

4. Carpintero Moreno,E. and Stansby,P.K. 2019 The 6-float wave energy converter M4: ocean basin tests giving capture width, response and energy yield for several sites, Renewable and Sustainable Energy Reviews ,104, 307-318.

5. Cieslikiewicz, W. and Gudmestad, O.T. 1994 Mass transport within the free surface zone of water waves, Wave Motion,19, 145-158.

6. Crespo, A.J.C. , Domínguez, J.M., Gómez-Gesteira, M., Hall,M., Altomare, C., Wu,M., Verbrugghe,T. , Stratigaki, V., Troch,P., Kisacik,D., Simonetti,I., Cappietti,L., Canelas,R.B., Ferreira, R.M.L., Stansby,P. 2018 Survivability of floating moored offshore structures studied with DualSPHysics, 13th SPHERIC workshop, Galway.

7. Davidson,J, and Ringwood, J.V. 2017 Mathematical Modelling of Mooring Systems for Wave Energy Converters-A Review, Energies, 10, 666. 
8. Duarte,T., Sarmento,A.JNA., Jonkman,J. 2014 Effects of Second-Order Hydrodynamic Forces on Floating Offshore Wind Turbines, NREL/CP-5000-60966, AIAA Sci Tech 2014 National Harbor, Maryland.

9. Eatock Taylor,R., Taylor,P.H. and Stansby, P.K. 2016 A coupled hydrodynamic-structural model of the M4 wave energy converter, J. Fluids and Struct. 63, 77-96.

10. Giorgi,G. and Ringwood, J.V. 2018 Comparing nonlinear hydrodynamic forces in heaving point absorbers and oscillating wave surge converters, J. Ocean Eng. Mar. Energy, 4, 25-35.

11. Gu,H., Stansby,P., Stallard,T., Carpintero Moreno,E. 2018 Drag, added mass and radiation damping of oscillating vertical cylindrical bodies in heave and surge in still water, J. Fluids Struct, 82, 343-356.20.

12. Hall, M., Buckham, B., Crawford, C. 2014 Evaluating the importance of mooring line model fidelity in floating offshore wind turbine simulations. Wind Energy, 17, 1835-1853.

13. Hall, M., Goupee, A. 2015 Validation of a lumped-mass mooring line model with DeepCwind semisubmersible model test data. Ocean Eng., 104, 590-603.

14. Hsu, S.A., E.A. Meindl, and D.B. Gilhousen, 1994, Determining the power-law wind-profile exponent under near-neutral stability conditions at sea, J. Appl. Meteor., Vol. 33, pp. 757765.

15. Hu,Z.Z., Greaves,D., Raby,A. 2016 Numerical wave tank study of extreme waves and wave-structure interaction using OpenFoam , Ocean Engineering 126, 329-342.

16. Jonkman,J., Butterfield,S., Musial,W., and Scott, G. 2009 Definition of a 5-MW Reference Wind Turbine for Offshore System Development, Technical Report NREL/TP-500-38060

17. Jonkman,J. and Sprague,M. 2018 National Wind Technology Center Information Portal (OpenFAST). https://nwtc.nrel.gov/OpenFAST. Last modified 05-January-2018; Accessed 27-February-2019

18. Karimirad,M. and Moan,T. 2012 Stochastic dynamic response analysis of a tension leg spartype offshore wind turbine, Wind Energ. 16, 953-973

19. Kim,J.H., Hong,S.Y. 2014 The Shape Design and Analysis of Floating Offshore Wind Turbine Structures with Damper Structure and Shallow Draft, J Oc Wind Energy, 1, 170-176

20. Koo,B.J., Goupee,A.J., Kimball,R.W., Lambrakos,K.F. 2014 Model Tests for a Floating Wind Turbine on Three Different Floaters, J Off Mech and Arc Eng, 136, 020907

21. Langley,R., S., 1986 On the time domain simulation of second order wave forces and induced responses, Applied Ocean Research, 8, 7-18.

22. Lee, C.H., and Newman, J. N., 2013, WAMIT - User manual version 7.0, WAMIT Inc, Chestnut Hill, Massachusetts.

23. Lind, S.J., Stansby, P.K., Rogers, B.D. 2016 Fixed and moored bodies in steep and breaking waves using SPH with the Froude Krylov approximation. J Ocean Eng Mar Energy, 2(3), 331354.

24. Liu Y, Xiao Q, Incecik A, Peyrard C, Wan D, 2017 Establishing a fully coupled CFD analysis tool for floating offshore wind turbines, Renewable Energy, 112 , 280-301

25. Mei,C.C. 1999 The applied dynamics of ocean surface waves, World Scientific, Singapore.

26. Oguz, E., Clelland, D., Day, A.H., Incecik, A., López, J.A., Sánchez, G., Almeria, G.G. 2018 Experimental and numerical analysis of a TLP floating offshore wind turbine. Ocean Eng., $147,591-605$. 
27. Roald, L., Jonkman, J., Robertson, A., Chokani, N. 2013, The Effect of Second-order Hydrodynamics on Floating Offshore Wind Turbine, NREL/CP-5000-58718, DeepWind'2013 10th Deep Sea Offshore Wind R\&D Conference Trondheim, Norway

28. Roddier,D., Cermelli,C., Aubault,A. and Weinstein,A. 2010 WindFloat: A floating foundation for offshore wind turbines, J.Renew Sustain En, 2, 033104

29. Santo,H., Taylor, P.H., Carpintero Moreno, E., Stansby,P., Eatock Taylor, R., Sun,L., Zang,J, 2017 Extreme motion and response statistics for survival of the three-float wave energy converter M4 in intermediate water depth, J. Fluid Mech., 81, 175-204.

30. Sjökvist,L., Wu,J., Ransley,E., Engström, J., Eriksson,M. and Göteman,M., 2017 Numerical Models for the Motion and Forces of Point-absorbing Wave Energy Converters in Extreme Waves, Ocean Engineering, , 145, 1-14.

31. Shore Protection Manual 1973, US Army Corps Engineers, Coastal Engineering Research Center, US Gov.Printing Office, Washington DC.

32. Skaare,B., Nielsen,F.G., Hanson,T.D., Yttervik, R., Havmøller,O., and Rekdal,A. 2015 Analysis of measurements and simulations from the Hywind Demo floating wind turbine, Wind Energy, 18, 1105-1122

33. Stansby,P., Carpintero Moreno,E., Stallard,T., 2017 Large capacity multi-float configurations for the wave energy converter M4 using a time-domain linear diffraction model, Applied Ocean Research , 68, 53-64.

34. Subbulakshmi n, A., Sundaravadivelu,R. 2016 Heave damping of spar platform for offshore wind turbine with heave plate, Ocean Engineering, 121, 24-36

35. Sun,L., Zang,J., Stansby,P., Carpintero Moreno, E., Taylor,P., Eatock Taylor,R. 2017 Linear diffraction analysis of the three-float multi-mode wave energy converter M4 for power capture and structural analysis in irregular waves with experimental validation, J. Ocean Eng. Mar. Energy, 3(1), 51-68.

36. Tao, L., and Thiagarajan, K. 2003 Low KC flow regimes of oscillating sharp edges. II. Hydrodynamic forces, Applied Ocean Research 25, 53-62. 